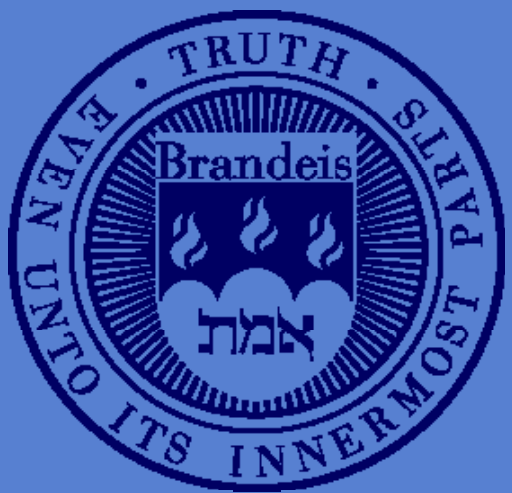

AGrowth Theory and Growth Accounting: Reformulating Our Understanding of Growth

Gary Jefferson, Economics Department, Brandeis University 


\title{
Growth Theory and Growth Accounting: Reformulating Our Understanding of Growth*
}

\author{
Gary H. Jefferson \\ jefferson@brandeis.edu \\ May 23, 2016; revision, July 14, 2016 \\ Initial Draft: comments are most welcome!
}

"There are always aspects of economic life that are left out of any simplified model. There will therefore be problems on which it throws no light at all; worse yet, there may be problems on which it appears to throw light, but on which it actually propagates error."

Robert M. Solow (2000, pp. 1,2)

\begin{abstract}
This paper seeks to address shortcomings in the growth literature - neoclassical growth theory and growth accounting. Specifically, the paper reformulates our understanding of the process of technical change, so that we view Hicks- and Harrod-neutral technical change as consistent, inseparable phenomena within a unified growth process. With this integrated Hicks-Harrod paradigm, the paper then: (i) reinterprets the steady state condition thereby clarifying the circumstances under which $\mathrm{s}, \mathrm{n}$, and $\delta$ are admissible, whereas g should be excluded, (ii) introduces the technology multiplier, which helps to restore technical change to its place as a public good, while creating new country-specific avenues for endogenous growth, (iii) opens a window for examining historic turning points in the growth experience, and (iv) introduces the Harrod-based accounting function thereby enabling the reconciliation and integration of growth theory and growth accounting. These reformulations substantially expand the boundaries of the neoclassical growth model to explore new avenues of growth that may be sufficient to explain the observed disparities in living standards across nations.

*The author deeply appreciates the helpful suggestions of George Hall, Fung Kwan, Dwight Perkins, Thomas Rawski, Su Jian, and Anthony Yezer, as well as the opportunities to present earlier drafts of the ideas in this paper to the Brown Bag Lunch Symposium of the Brandeis Economics Department and at the School of Economics, the University of Macao. The contribution of Wei Jia to producing the figures in the paper is also much appreciated. Errors and omissions that persist remain solely the responsibility of the author.
\end{abstract}




\section{Introduction}

This paper is both ambitious and seemingly rather implausible. In their introduction, Aghion and Howitt (2007, p. 79) write:

Fifty years after its publication, the Solow model remains the unavoidable benchmark in growth economics, the equivalent of what the Modigliani-Miller theorem is to corporate finance, or the Arrow-Debreu model is to microeconomics. And there are at least two good reasons for this. First, with only two equations (the production technology and the capital accumulation equations) the Solow model sets the standards of what a parsimonious and yet rigorous growth model should be. Second, the model shows the impossibility of sustained long-run growth of per capita GDP in the absence of technological progress.

In the conclusion to Ch. 8, “The Neoclassical Growth Model” in his textbook, Acemoglu (2009, p. 317) takes stock: "This chapter presented arguably the most important model in macroeconomics.” Finally, Jones and Romer (2010, p. 225) make the claim: “There is no longer any interesting debate about the features that a model must contain to explain (the Kaldor facts). These features are embedded in one of the great successes of growth theory in the 1950s and 1960s, the neoclassical growth model.”

And yet, the conventional representation of the neoclassical growth model rests on one key assumption that many find curious, indeed implausible: that is, that the nature of technical change is “purely labor-augmenting,” otherwise known as Harrod-neutral. ${ }^{1}$ Solow himself writes: “...it is possible to give theoretical reasons why technological progress might be forced to assume the particular form ("called labor-augmenting”) required for the existence of a steady state. They are excessively fancy reasons, not altogether believable.” (2000, pp. 32) Others, including Acemoglu (2009, p. 62), also resist the intuition that balanced growth requires technical change to be solely labor augmenting, referring to the result as "At some level...distressing."

While accepted as a convenience that enables a certain internal consistency required to represent the steady state balanced growth equilibrium, the assumption of "purely labor

\footnotetext{
${ }^{1}$ Recall that the principal alternative to Harrod-neutral technical change is Hicks-neutrality involving equiproportional increases in the marginal products of both capital and labor, which is equivalent to relabeling the isoquants. Harrod-neutral technical change results in an increase in the marginal product of labor only and hence is "purely labor-augmenting. "
} 
augmenting" technical change also imposes serious limitations on the potential for growth theory, as well as creating an estrangement with its real-world cousin, growth accounting.

Against this background, this paper addresses serious shortcomings and inconsistencies in the growth theory and growth accounting literature that have emerged and compounded over the past 60 years since Solow published his seminal growth theory paper in 1956. If this paper were to be compressed into an essay that addresses vexing puzzles that afflict growth theory, three of these would be: i) If the intrinsic nature of technical change is that it is "purely labor augmenting," why is it that over time we observe physical goods and human capital becoming increasingly technologically sophisticated?; ii) With the requirement that the nature of the underlying inventions be publicly disclosed and the fruits of technical change visibly disseminated around the world, why, in accord with the Solow model, does technical change not enter into the international domain more as a public good, so that income disparities across countries are not so large?; and iii) Within the economics discipline, why have growth theorists and growth accountants been unable to integrate their fields so as to provide a coherent, integrated understanding of the nature of economic growth?

Expressed concisely, the purpose of this paper is to revisit both growth theory and growth accounting with a view toward addressing these puzzles by amending and extending the original neoclassical growth model to clarify the respective roles of Hicks- and Harrod-neutral technical change and thereby highlight the critical role that capital's output elasticity plays while also reconstructing the two streams of growth analysis - neoclassical growth theory and growth accounting - now divorced, to share a uniform set of assumptions and methods that will enable the creation of a single, integrated perspective on the theory, process, and measurement of economic growth.

\section{Reinterpreting Balanced Growth}

Kaldor (1957) characterized the stylized facts of long-run growth. These include three essential features: a capital-output ratio, the return on capital, and factor income shares that are largely fixed over long periods of time. We begin the analysis with the proposition that the most accurate and concise way to represent these stylized facts is with the following two-equation model:

$$
\mathrm{y}=\mathrm{Ak}^{\alpha}
$$




$$
\mathrm{k} / \mathrm{y}=\mathrm{V} \text {. }
$$

where $y=Y / L, k=K / L$, and A is a measure of technology. Eq. (1) is a standard intensive form of a constant-returns-to-scale Cobb-Douglas production function. A represents technical change as Hick-neutral, meaning that it is represented as equi-proportional increases in the marginal products of both labor and capital, measured at the existing capital-labor ratio before the system has had a chance to adjust to any technological shock.

Contrasted with Solow's model (1956), as a representation of Kaldor's stylized facts of economic growth, we have constructed the model in its most simple form. By embedding two restrictions in the model - fixed factor income shares in Eq. (1) and a fixed capital-output ratio in Eq. (2) - each of the other four stylized facts follows conditional on a positive rate of technical change over long periods of time. ${ }^{2}$

In the Solow model and subsequent elaborations in the growth theory literature, the $\mathrm{V}$ vector consists of the savings rate, population growth, and the rate of depreciation. For the case in which on-going technical change exists, the growth literature further includes in $\mathrm{V}$ the rate of growth of Harrod-neutral labor-augmenting technical change. A central proposition of this paper is that Eq. (1) representing technical change as Hicks-neutral is the preferred representation - a representation which is not inconsistent with the Harrod version of technical change. We also show in Section 4 that with g representing the rate of growth of Hicks-neutral technical change, $g$ becomes extraneous to the steady state equation.

Solving the two-equation system for the steady-state capital-labor ratio, $\mathrm{k}^{*}$, results in $\mathrm{k}^{*}$ $=(\mathrm{AV})^{1 /(1-\alpha)}$. Substituting $\mathrm{k}^{*}$ back into the intensive production function yields $\mathrm{y}^{*}=\mathrm{A}^{1 /(1-\alpha)} \mathrm{V}^{\alpha /(1-\alpha)}$. In rate-of-change form, where $\wedge$ represents a rate of growth, the system becomes:

and

$$
\mathrm{k}^{* \wedge}=[1 /(1-\alpha)]\left(\mathrm{A}^{\wedge}+\mathrm{V}^{\wedge}\right)
$$

$$
\mathrm{y}^{* \wedge}=[1 /(1-\alpha)] \mathrm{A}^{\wedge}+[\alpha /(1-\alpha)] \mathrm{V}^{\wedge}
$$

\footnotetext{
${ }^{2}$ The remaining four stylized facts are that, over long periods of time: (i) the rate of growth of the capital stock per worker is roughly constant, (ii) the rate of growth of output per worker is roughly constant, (iii) the rate of return on investment is roughly constant, and (iv) the real wage grows.
} 
This formulation makes clear that so long as the $\mathrm{V}$ vector remains time invariant, the rates of growth of both output per capita and the capital-labor ratio remain fixed and are determined exclusively by the rate of Hicks-neutral technical change. ${ }^{3}$ That the coefficients on $\mathrm{A}^{\wedge}$ are identical for the two equations confirms that the $\mathrm{k} / \mathrm{y}$ ratio is fixed irrespective of the rate of growth of $\mathrm{A}$. That the coefficients on $\mathrm{V}^{\wedge}$ differ as between $\mathrm{k}^{* \wedge}$ and $\mathrm{y}^{* \wedge}$ demonstrates why changes in the elements of $\mathrm{V}^{\wedge}$ will lead to changes in the capital-output ratio.

To contrast the balanced growth condition under the assumption of Hicks-neutral technical change with its Harrod-neutral counterpart, we derive the balanced growth equations using the standard Harrod version of the production function: $Y=K^{\alpha}(A L)^{1-\alpha}$. Incorporating Eq. (2) as shown above yields the Harrod version of the balanced growth conditions:

and

$$
\mathrm{k}^{* \wedge}=\mathrm{A}^{\wedge}+[1 /(1-\alpha)] \mathrm{V}^{\wedge}
$$

$$
\mathrm{y}^{* \wedge}=\mathrm{A}^{\wedge}+[\alpha /(1-\alpha)] \mathrm{V}^{\wedge} .
$$

Note that Eqs. (4) and (6) - the Hick and Harrod versions respectively - are identical except for the coefficients on $\mathrm{A}^{\wedge}$; we designate these coefficients on $\mathrm{A}^{\wedge}$ as technology multipliers.

This formulation, as well as the Hicks version in Eqs. (3) and (4), makes clear that so long as the $\mathrm{V}$ vector remains time invariant, the rates of growth of both output per capita and the capital-labor ratio remain fixed and are determined exclusively by the rate of technical change. That the coefficients on $\mathrm{V}^{\wedge}$ differ as between $\mathrm{k}^{* \wedge}$ and $\mathrm{y}^{* \wedge}$ demonstrates why changes in the elements of $\mathrm{V}$ will lead to changes in the capital-output ratio. That the coefficients on $\mathrm{A}^{\wedge}$ are identical for the two equations in each system confirms that the $\mathrm{k} / \mathrm{y}$ ratio is fixed irrespective of the rate of growth of A or changes in its rate of growth - provided that $\mathrm{A}^{\wedge}$ (i.e., g), ${ }^{4}$ is not an argument of the $\mathrm{V}$ vector.

Fig. 1 shows the balanced growth path (BGP). Since the K-Y (and k-y) ratio is fixed by $\mathrm{V}$ for both the Hicks and Harrod-neutral cases, the BGP is identical for either characterization of technical change. The key difference between the Hicks’ representation and the Harrod representation, as summarized in paragraph (iii) below and analyzed in Section 5 , is that as a

\footnotetext{
${ }^{3}$ In his demonstration that with Hicks-neutral technical change balanced growth is impossible, Solow actually made an error in his seminar article (1956, p. 63 ). The error arises from substituting his expression for $\mathrm{K}^{\wedge}$ into a production function in which he mistakenly dropped the $A$ term representing Hicks neutral technical change. Had he retained the $A$ term, his derivation could have shown that $k^{\wedge}=y^{\wedge}$; thus, for a given $g, k^{\wedge}-y^{\wedge}=0$, ensuring a steady-state $\mathrm{K}-\mathrm{Y}$ ratio.

${ }^{4}$ The paper uses $A^{\wedge}$ and $g$ interchangeably.
} 
result of the Hicks version yielding a larger technology multiplier than its Harrod counterpart, equivalent amounts of technical change (e.g., a change from $A_{0}$ to $A_{1}$ ) shift the production function up along the BGP further for the Hicks case, thereby raising living standards more rapidly for the Hicks version than for the Harrod version. This will be further illustrated in Fig. 3 when we return to this matter in Section 5.

As a way of summarizing the arguments and organization of the paper, we specify five implications of Eqs. (3) and (4), based upon their comparisons with Eqs. (5) and (6).

i) The first is that Hicks-neutral technical change is consistent with a balanced growth path in which the K-Y ratio remains fixed, so long as the elements of the $\mathrm{V}$ vector are unchanged. This result runs contrary to the long-held, but fundamentally misconstrued assumption that balanced growth requires technical change to be "purely labor augmenting." More fundamentally, we show that Hicks and Harrod-neutral technology are complementary phenomena that are part of the same dynamic process of technological advance. The formulation of this integrated Hicks-Harrod paradigm, a matter of some importance, is clarified and elaborated in Section 3, the following sector.

ii) Second, Section 4 examines in more depth than otherwise available in the literature the logic of the arguments that form the $\mathrm{V}$ vector. Specifically, we show the importance of the respective roles of factor bias/neutrality and the partial adjustment investment mechanism for framing the role of the factors that belong in the steady-state equation. We show that when $\mathrm{g}$ is measured as Hicks-neutral technical change it does not belong in the steady state equation, nor under a reasonable assumption should Harrod-neutral technical change be included.

iii) The third feature of Eqs. (3) and (4) is that both equations embody a technology multiplier equal to $1 /(1-\alpha)$, which underscores the importance of the magnitude of $\alpha$, capital's output elasticity and its role in shaping long-run growth. For values of $\alpha$ such that $0<\alpha<1$, the Hicks technology multiplier lies in the range $1<\theta<\infty$. This result contrasts with that associated with Harrod-neutral technical change for which the technology multipliers, shown in Eqs. (5) and (6) are always constrained to unity, regardless of the size of capital's elasticity. The introduction of this technology multiplier makes more plausible the public good character of technical innovation. Section 5 focuses on the technology multiplier. It also explains why and how technical change should be understood and modeled differently for frontier economies and catchup economies.

iv) The shift from solely Harrod to the integrated Hicks-Harrod paradigm of technical change and the dynamic growth process with its focus on the ex ante event of Hicks “invention neutrality” followed by the ex post Harrod steady-state neutrality yields significant implications for framing endogenous growth theory. In Section 6, we examine the implications of the existence of the technology multiplier for strains of the 
existing endogenous growth literature. We then identify an alternative vision for endogenous growth theory, which clearly distinguishes between two distinct stages of global growth: the transformation of initial Hicks invention neutral innovation to Harrod technologies in frontier countries, followed by the absorption of the public-good Harrod technology to elevate living standards in catch-up countries. In this section, we further suggest that the central role of the technology multiplier behooves us to balance our preoccupation with steady state growth with greater attention to turning points in growth trajectories, i.e., changes in $\alpha$ and $V$ that cause nations to veer off one balanced growth path to another higher or lower path. A key finding is the importance of the level of the savings rate as a determinant of the magnitude of the technology multiplier and the steady-state rate of growth of income per capita.

v) The fifth and final implication of this revision of growth theory is that the analysis carries deep implications for growth accounting. While in Sections 2 through 6, the HicksHarrod paradigm is used to justify the argument that growth theory should be developed on the foundation of Hicks-neutral technical change with the Hick-based inventionproduction function as its starting point, Section 7 uses the same integrated framework to introduce the Harrod-based accounting function as the appropriate tool for conducting growth accounting. Given the task of growth accounting comparing two actual or quasisteady-state long-period conditions, the relevant technology now becomes that of Harrodneutral technical change. With this change and with the additional recognition on the growth-accounting side that capital deepening is a fundamentally endogenous process an assumption already embedded into the Harrod-based accounting function - this paper should enable growth theory and growth accounting to share a sufficiently uniform set of economic assumptions and principles, so that these two streams of growth analysis can be used in a consistent and complementary manner.

Section 8 presents concluding remarks.

\section{Reconciling Hicks and Harrod-Neutral Technical Change in Growth Theory ${ }^{5}$}

Conventional presentations of neoclassical growth theory are correct in their claim that in the steady-state, technical change is appropriately represented as labor-augmenting, otherwise known as Harrod-neutral. Indeed, once the system has reached the steady-state in which Kaldor's various growth “facts” emerge, technological progress exhibits all the features of Harrod-neutral technical change. Uzawa (1961) has famously demonstrated this, while others, including Jones and Scrimgeour (2005), have offered more intuitive explanations of this condition.

\footnotetext{
${ }^{5}$ Throughout this paper, we refer to the advance of living standards as "technical change." It must be emphasized at the outset that technical change is but shorthand for a variety of sources of productivity growth, which includes both technical innovation and institutional innovation, both broadly defined - as well as their interactions.
} 
However, although the established representation of technical change in the steady-state is relevant, the literature portraying the nature of technical change in neoclassical growth as Harrod-neutral is fundamentally mistaken. Given that the formulation of the neoclassical growth model requires the assumption of some stylized version of technical change, whether favoring Harrod, Hicks, or Solow-neutrality, ${ }^{6}$ the most appropriate version is that of the Hicks variety in which labor and capital exhibit "invention neutrality" leading directly to equi-proportional increases in their marginal products at the initial capital-labor ratios.

After characterizing the Uzawa Theorem that shows that steady-state balanced growth requires technical change to be solely labor augmenting as "At some level...distressing." Acemoglu (2009, p. 62) further qualifies the Steady-State Theorem suggesting that it “(does) not state that technical change has to be labor-augmenting all of the time," Solow (2000, p. 32) downgrades the phenomenon of purely labor-augmenting technical change as simply "a metaphor.” The hedging on this matter is a curious paradox of neoclassical growth theory. In any event, Acemoglu's textbook (2009) and every other description of the neoclassical model employs representations of the basic production function in which technical change is, in fact, purely labor augmenting "all of the time."7

This is deeply ironic. The economics literature has failed to appreciate a fundamental feature of the nature of technical change. That is, the representations of Hicks and Harrodneutral technical change are not only not inconsistent, they are fundamentally inseparable. Hicks' representation of technical change entails capital and labor exhibiting equi-proportional increases in their marginal products, holding fixed the initial capital-labor ratio. By comparison, Harrodneutral change characterizes the change in the system, after it has adjusted, i.e., following the process of capital deepening that ensues from capital and labor-augmenting technical change and a rise in the capital-labor ratio to its eventual new steady-state level at which point the marginal product of capital and the returns to capital have been driven back to their original levels.

\footnotetext{
${ }^{6}$ Solow-neutral technical change is technical change that is purely capital-augmenting.

${ }^{7}$ One notable exception to this established, and generally unchallenged, practice of representing technical change as "purely labor augmenting" is Grossman et al (2016) in which they identify specific conditions - i.e., schooling is endogenous and capital is more complementary with schooling than with raw labor - that allow for some degree of capital-augmenting technology. While this approach is able to partially skirt Uzawa's Theorem, it requires the negation of the key "Kaldor facts", i.e., the factor income shares, the K-Y ratio, and returns to capital are generally fixed over time.
} 
Succinctly put, the condition of on-going Harrod-neutral technical change should be viewed as an outcome of the on-going process of Hick-neutral technical change. ${ }^{8}$

In his correspondence with Harrod, Hicks chooses to emphasize that his classification and that of Harrod share a fundamental difference: while Hicks focuses on short-run "invention neutrality” holding the capital stock fixed, Harrod's definition characterizes the long-period equilibrium in which the capital stock has adjusted to a new equilibrium. According to Hicks:

Your theory, as I now see it, is a long-period theory where (in equilibrium) the supply of capital (i.e. the stock of capital) is not an independent but a dependent variable, adjusting itself to the other data of the system, such as the rate of growth. In such a system a definition of "invention neutrality" such as mine is not possible; one has to have a definition of the same type as yours, into which the stock of capital does not explicitly enter. Basically this is because in your system it is the same equilibrium when capital has doubled and everything else has doubled, as it was before...." 9

The frustrating irony is that Hicks and Harrod were not able to come to terms with the fact that the two characterizations were "peas in a pod" representing a single integrated process of innovation leading to economic growth. In this process of technological advance, Hick's "invention neutral" technical change is a pre-condition for creating the necessary disequilibrium that motivates growth in the capital stock leading to the capital deepening required to drive the economy to a new equilibrium with a higher capital-labor ratio while restoring the steady-state capital-output ratio and the returns to capital to their historic levels.

The sequential complementarity of Hicks-Harrod technical change is shown in Fig. 2. The initial Hicks-neutral capital-and-labor-augmenting technical change is represented by the upward shift in the intensive production function from $\left(\mathrm{y}_{0}{ }^{*}, \mathrm{k}_{0}{ }^{*}\right)$ to $\left(\mathrm{y}_{1}, \mathrm{k}_{0}{ }^{*}\right)$. This technical innovation in which the K-L ratio is unchanged is consistent with Hicks' representation of technical change. ${ }^{10}$ Thereafter, with capital's marginal product having risen and capital being endogenously reproducible, capital deepening ensues as the economy moves along the production function from $\left(\mathrm{y}_{1}, \mathrm{k}_{0} *\right)$ to $\left(\mathrm{y}_{1} *, \mathrm{k}_{1} *\right)$. Indeed, at $\left(\mathrm{y}_{1} *, \mathrm{k}_{1} *\right)$, the economy takes on all the appearances of having been transformed by labor-augmenting technical change exclusively in which only the marginal product of labor has risen, while that of capital, having converged

\footnotetext{
${ }^{8}$ This is demonstrated in Annex B and specifically in Fig. B-1, as explained later in this section.

${ }^{9}$ Hicks to Harrod, 30 January 1963, see also Hicks 1963, pp. 348-350, reproduced in Besomi, 1999.

${ }^{10}$ Jones $(1975$, p. 164-65) shows geometrically that the increase in capital and labor's marginal products are equiproportional.
} 
back to its original level, is unchanged, consistent with Harrod's characterization and Kaldor's stylized facts.

Against the background of this intuition, we revisit the Steady-State Growth Theorem, formulated by Uzawa (1961), that requires technical change to be of the labor-augmenting variety, i.e., Harrod-neutral, not Hick-neutral. As explained by Jones and Scrimgeour (2005, p. 4), Uzawa's Theorem reads:

If a neoclassical growth model possess a steady state with constant, non-zero factor shares and $\mathrm{y}_{\mathrm{t}}{ }^{\wedge} \mathrm{y}_{\mathrm{t}}=\mathrm{g}>0$, then it must be possible along the steady-state path to write the production function as $Y=G\left(K_{t} ; A_{t} L_{t}\right)$, where $A_{t} \wedge / A_{t}=g$ and where $G$ is a neoclassical production function.

Jones and Scrimgeour (2005, p. 2) note, “...the modern reader of Uzawa will be struck by two things. The first is the lack of a statement and direct proof of the steady-state growth theorem. The second is the absence of economic intuition, both in method and more generally in the paper.” Setting out to remedy these two shortcomings of the original Uzawa (1961) paper, Jones and Scrimgeour provide a straightforward and transparent interpretation of the requirement of laboraugmenting technical change. Starting with the general form of the production function, $\mathrm{Y}=$ $\mathrm{F}(\mathrm{K}, \mathrm{L}, \mathrm{t})$, they divide both sides of the production function by output. This yields the "balance" expression:

$$
1=\mathrm{F}(\mathrm{K} / \mathrm{Y} ; \mathrm{L} / \mathrm{Y} ; \mathrm{t})
$$

or

$$
1=F\left(K_{t} / Y_{t} ; 1 / y_{t} ; t\right) .
$$

In the steady state, the capital-output ratio must be constant and $\mathrm{y}_{\mathrm{t}}$ grows at a constant exponential rate. To satisfy the balance equation, technical change must exactly enable "effective labor" to grow at the rate of growth of $\mathrm{y}_{\mathrm{t}}$. That is, technical change must be labor augmenting.

A still more intuitive way to make the argument is posed by Acemoglu (2009). That is, given that balanced growth requires that $g_{K}=g_{Y}$, there are two possibilities. Each must enable the growth of the effective labor force to equal $g_{K}$ and $g_{Y}$. The first possibility is that the rate of growth of population equals $g_{K}$ and $g_{Y}$; for this case, there would no technical change. The more relevant case is that for which $g_{K}=g_{Y}>n$. As Acemoglu (2009, p. 62) explains: “...(this) 
case creates an asymmetry between capital and labor, in the sense that capital is accumulating faster than labor. Constancy of growth then requires technological change to make up for this asymmetry - that is, technology should take a labor-augmenting form.”

Annex A and Figs A-1 and A-2 demonstrate the implausible case in which technical change is purely labor-augmenting throughout the growth process, such that capital "inherits the trend in $\mathrm{A}_{\mathrm{t}} \mathrm{L}_{\mathrm{t}}$ " as postulated by Jones and Scrimgeour. ${ }^{11}$ Fig. A-1 is the conventional steady state representation shown in textbook accounts of the neoclassical growth steady state with technical change. ${ }^{12}$ Fig. A-2 maps the properties implicit in the savings function in Fig. A-1 into a production function with the same concavity and embedded capital-effective labor ratio, $\mathrm{k}_{0}^{\sim}$. Technical change enters by enlarging A, which initially causes the economy to retreat back along the production function from $\left(\tilde{\mathrm{y}}_{0}{ }^{*}, \mathrm{k}_{0}{ }^{*}\right)$ to $\left(\tilde{\mathrm{y}}_{1}, \mathrm{k}_{1}\right)$. Following the increase in laboraugmenting technical change, the increase in the effective labor supply, a complement to capital, elevates capital's marginal product. For the case in which the substitution elasticity, $\sigma,=1$, the labor augmenting technical change raises the marginal products of capital and labor in equal proportions. The increase in capital's marginal product, in turn, attracts the additional available savings resulting from the increase in $\mathrm{Y} / \mathrm{L}$ due to the labor-augmenting technical change. As capital deepening ensues, capital “inherits” A, as postulated by Jones and Scrimgeour (2005), until the system returns to its original equilibrium at $\left(\mathrm{y}_{0}^{\sim}, \mathrm{k}_{0}^{\sim}\right)$.

However, the problem with capital inheriting labor's A alone, is that it may or may not contain any quality upgrading for the capital stock. Were the initial technical change solely labor-biased, while the technology parameter, A, could include new labor-augmenting software skills, it could not include the technology-augmented computers required for their applications. In Figure A-2, there is no upward shift in the effective-labor intensive production function, the increase in capital's marginal product results exclusively from the complementarity of primitive capital with the increasing supply of "effective labor." The intrinsic efficiency and marginal productivity of capital in its original state is unaffected by labor-augmenting technical change. So long as the supply of primitive capital enables the accumulation of rocks, soil, and trees to be perfectly elastic, so that their stock expands equi-proportionately with A and capital's marginal product converges to its historic level, capital and labor's factor income shares will remain

\footnotetext{
${ }^{11}$ Note that while Jones and Scrimgeour posit that capital "inherits the trend in $A_{t} L_{t}$," Acemoglu is suggesting that $A_{t} L_{t}$ is having to inherit the trend in $g_{k}$.

${ }^{12}$ See, for example, Jones and Vollrath (2013), p. 46, Fig. 2.9.
} 
fixed. ${ }^{13}$ One can readily understand why Solow characterized this account of growth as "fanciful" and Acemoglu (2009, p. 59) further characterized it as "very surprising and troubling."

The sequential nature of technical change. One key insight that frames this discussion is the following. In microeconomics textbooks, Harrod, Hicks, and Solow technical change is represented as each altering the production isoquant in different ways. Hicks neutral change simply entails renumbering the isoquants; Harrod-neutral change requires shifting in the labor portion of the isoquant only; Solow-neutral change shifts in the capital portion only. ${ }^{14}$

Unfortunately, this representation obscures the critical differences suitable for classifying technical change, both in its cross-section, at a moment in time, and also over time as it unfolds from the initial invention to the final steady state. The distinction between generic factor augmenting technical change in which a whole locus of $(\mathrm{K}, \mathrm{L})$ combinations become more efficient and Harrod technical change, which exists only in the steady state is demonstrated in Annex B. Fig. B-1 shows that for the purpose of characterizing shifts in isoquants resulting from new inventions, Hicks-neutral technical change should retain its conventional characterization. However, what is generally referred to as Harrod-neutral change should instead be characterized as labor-augmenting or labor-saving change. With the same amount of capital, with laboraugmenting technical change it becomes possible to produce the same output with less labor; hence, the isoquant shifts toward the capital axis. For the case of $\sigma=1$, at the initial K-L ratio, labor's MPL has risen relative to that of the MPK. By definition, Harrod neutrality emerges only for a steady-state equilibrium at which the K-Y ratio is held fixed and constant for both the Hicks and labor-biased technical change. ${ }^{15}$ At this point, after the two technologies have converged to an equilibrium in which $r=\alpha(Y / K)$, the Hicks-neutral innovations become observationally equivalent to the labor-biased technical change. Both have transformed into a steady-state, which has the characteristics of Harrod-neutral technical change in which only labor's marginal product has risen and capital's marginal product is unchanged.

\footnotetext{
${ }^{13}$ In order for this scenario to confirm to Kaldor's stylized facts and the properties of Harrod-neutral technical change, the supply of primitive capital would have to be effectively infinite and perfectly elastic. With increments to A, the "investment demand" schedule would shift successively to the right, allowing for increases in the K-L ratio with relatively constant marginal productivity and returns to capital.

${ }^{14}$ As more thoroughly explained in Appendix B, Acemoglu (2009, p. 59), for example, mistakenly applies this conventional approach to shifting isoquants to Harrod-neutral technical change.

${ }^{15}$ Note that for $\sigma=1$, for the purpose of arriving at the Harrod-neutral steady-state, the choice of technologyHarrod-neutral, labor-biased, or capital-biased - is immaterial. The Non-Identification Theorem, formulated by Diamond-McFadden-Rodriguez (1978), postulates that it may not be possible to distinguish between the magnitude of $\sigma$ and the initial factor bias.
} 
In our scheme of technical change in growth theory, Harrod change materializes only after the adoption and implementation of Hicks' invention technology. Harrod-neutral technical change is not an isoquant; it is an expansion ray as in $\mathrm{K}_{0} \mathrm{LHA}$ in Fig. B-1 along which the marginal product of labor rises as the capital-output ratio and the marginal product of capital are fixed. It is the outcome of Hicks invention-neutral technical change. We designate this single, integrated interpretation of technical change as the "Hicks-Harrod Paradigm.” This paradigm, which is essential to our method of modeling economic growth is of far greater importance than the mere placement of the A term in a multiplicative production function. It introduces sanity into the role of innovation in the growth process: innovation consists of an approximate balance of innovations that at given K-L ratios enhance the technical efficiency of both capital and labor.

The arithmetic link between measures of Hicks and Harrod-neutral technical change can be shown using Eqs. (4) and (6). Letting the Hicks version be denoted as $A_{1}$ and Harrod as $A_{2}$, representing their sequence in the process of technological advance, the two equations can be solved to show that $A_{1} \wedge=(1-\alpha) A_{2} \wedge$, so that $A_{2} \wedge=1 /(1-\alpha) A_{1} \wedge$. Since $A_{1} \wedge$ and $A_{2} \wedge$ each motivates the same $\mathrm{y}^{\wedge}$ and because Hicks-neutral technical change is both capital and labor augmenting, i.e., $\alpha A_{1} \wedge+(1-\alpha) A_{1} \wedge$, it is intuitively sensible that $A_{2} \wedge>A_{1} \wedge$. As shown in Fig 2, once the Hick-neutral technical change has materialized, the physical capital deepening process "inherits" the $\alpha \mathrm{A}_{1} \wedge$ portion of the "invention neutrality," further enlarging the effectiveness of labor from the initial impulse of $A_{1} \wedge$ until it grows to magnitude $A_{2} \wedge$. Hence the initial Hickneutral capital-augmenting technical change is not lost to the economy; with capital deepening, labor inherits the initial gain in capital's productivity, so that the system converges to "purely labor-augmenting" technical change. Again, because its cumulative effect is summarized by its effect on labor alone, $\mathrm{A}_{2} \wedge$ must be larger than $\mathrm{A}_{1} \wedge$, which, contrary to Harrod technical change, is able to act through two or more factors. This sequence of events is shown in Fig. 2, in which $\mathrm{A}_{1}=\left(\mathrm{y}_{1}-\mathrm{y}_{0} *\right)$ and $\mathrm{A}_{2}=\left(\mathrm{y}_{1} *-\mathrm{y}_{0} *\right)$.

4. Characterizing the V-vector and the Steady State

By fixing the capital-output ratio, such that $K / Y=V$, Eq. (2), serves to clarify the essential function of the second equation in the neoclassical growth model, which is to specify a given capital-output ratio consistent with Kaldor's stylized facts. And yet, as shown in Eqs. (4) and (6), so long as $V$ is fixed, the actual capital-output ratio has no bearing on the steady state 
rate of growth of output per capita, which is determined solely by $\mathrm{A}^{\wedge}$. In this section, we accept this conventional understanding; the next section provides alternative interpretations of the roles of $\mathrm{V}$ and $\mathrm{V}^{\wedge}$ in the growth process.

In the standard presentation of the neoclassical growth model, the steady-state equation including $\mathrm{s}, \mathrm{n}, \mathrm{g}$, and $\delta$ is used to identify the relevant $\mathrm{K} / \mathrm{Y}, \mathrm{K} / \mathrm{L}$ and $\mathrm{K} / \mathrm{AL}$ ratios. These parameters are the elements of the $\mathrm{V}$-vector that appear in the parsimonious functional form of Eq. (2). Thus, as elements of $\mathrm{V}$, so long as the four parameters are stable, their values have no bearing on the steady-state rate of growth of output per capita.

To the extent that the $\mathrm{V}$ vector is stationary, $\mathrm{V}$ stands as a second-order element of the growth story. If, however, the relevant elements of the vector are substantially time variant, and responsive to policy or structural change in the economy, particularly in some predictably and measurable way that conforms with economic theory and empirical experience, say structural change associated with the development process, then the $\mathrm{V}$ vector should receive greater attention in growth theory modeling. Again, the ways in which the absolute value of the Vvector may matter for steady-state growth will be addressed in the next section.

While most textbooks present the mathematical derivation for the standard steady-state equation as $s y=(n+\delta+g) k$, they do not attempt to explain the economic intuition concerning why, given certain restrictions, an equi-proportional change in the rates of savings, population growth, capital depreciation, or labor-augmenting technical change should have identical impacts on the $\mathrm{K}-\mathrm{Y}$ ratio. We address these matters below.

Overview. Although the four parameters $\mathrm{s}, \delta$, n, and g seemingly enter the steady-state condition in a symmetric way, the savings rate and rate of depreciation operate on the K-Y ratio in ways that are fundamentally different than the ways in which the rates of population growth and labor-augmenting technical change affect the steady state. This is because the first two of these factors $-\mathrm{s}$ and $\delta$ - affect the physical quantity of capital while having no impact on the physical quantity of labor, for which the quantity is exogenously fixed. Conversely, by directly affecting the effective supply of labor, changes in $n$ and g alter output, thereby disrupting capital's equation of motion and leading to physical changes in the capital stock as endogenously determined by the equation of motion. However, due to the partial adjustment process of the capital stock, increases in $\mathrm{n}$ and $\mathrm{g}$ alter the capital stock with a lag in relation to the instantaneous 
change in the effective supply of labor, thus causing $\mathrm{Y}$ to increase by more than $\mathrm{K}$, leading to a decline in the K-Y ratio.

First we ask: If changes in $\mathrm{s}$ and $\delta$ and $\mathrm{n}$ and $\mathrm{g}$ alter the steady state due to their different factor biases, is the K-Y ratio affected by conditions that are factor-neutral?

Factor-neutral change: Based on the above analysis, one might anticipate that the critical condition that requires a condition to be included in the steady state equation is that it be factorbiased, such that it affects the effective supply of capital and labor differently and therefore creates new steady-state outcomes in which the K-Y ratio is altered. We offer the example of the conventional distinction between Hicks and Harrod-neutral technical change in which the former is augmenting for all factors whereas the augmenting effect of the latter is biased toward labor.

The standard textbook presentation of the impact of $\mathrm{g}$ on $\mathrm{K} / \mathrm{Y}$ starts with the investment equation of motion:

$$
\begin{aligned}
& \mathrm{dK}=\mathrm{s} Y-\delta \mathrm{K} \\
& \mathrm{dK}=\mathrm{dK} / \mathrm{dt} \\
& \mathrm{dK} / \mathrm{K}=\mathrm{sY} / \mathrm{K}-\delta
\end{aligned}
$$

Assume two conditions: $\mathrm{L}_{\mathrm{t}}=\mathrm{L}_{0} \mathrm{e}^{\mathrm{nt}}$ and $\mathrm{A}_{\mathrm{t}}=\mathrm{A}_{0} \mathrm{e}^{\mathrm{gt}}$, so that $\mathrm{A}_{\mathrm{t}} \mathrm{L}_{\mathrm{t}}=\mathrm{L}_{0} \mathrm{e}^{(\mathrm{n}+\mathrm{g}) \mathrm{t}}$

Given the above, with population growth and Harrod-neutral technical change, the steady state requires that K/AL be constant; hence, in the steady state:

$$
\begin{aligned}
& \mathrm{dK} / \mathrm{K}-(\mathrm{dA} / \mathrm{A}+\mathrm{dL} / \mathrm{L})=\mathrm{dk}^{\sim} \mathrm{k}^{\sim}=0 . \\
& \mathrm{dK} / \mathrm{K}-(\mathrm{dA} / \mathrm{A}+\mathrm{dL} / \mathrm{L})=\mathrm{dk}^{\sim} / \mathrm{k}^{\sim}=\mathrm{sY} / \mathrm{K}-(\mathrm{n}+\mathrm{g}+\delta)
\end{aligned}
$$

Multiplying both sides of Eq. (7) by $\mathrm{k}^{\sim}$ and setting $\mathrm{dk}^{\sim}=0$ gives the conventional steady state equation, i.e., $\mathrm{s} \mathrm{y}^{\sim}=(\mathrm{n}+\mathrm{g}+\delta) \mathrm{k}^{\sim}{ }^{16}$

As in Section 3, let's now assume that technical change is of the Hicks-neutral variety, so that Eq. (7) becomes:

$$
[(\mathrm{dA} / \mathrm{A}+\mathrm{dK} / \mathrm{K})]-[(\mathrm{dA} / \mathrm{A}+\mathrm{dL} / \mathrm{L})]=\mathrm{dk} / \mathrm{k}=\mathrm{sY} / \mathrm{K}-(\mathrm{n}+\delta)
$$

\footnotetext{
${ }^{16}$ Note that $k^{\sim} / y^{\sim}=y / y=K / Y=s /(n+g+\delta)$.
} 
That is, in the steady state equilibrium, $\left[\left(\mathrm{A}_{\mathrm{t}}-\mathrm{A}_{0}\right) / \mathrm{A}_{0}+\left(\mathrm{K}_{\mathrm{t}}-\mathrm{K}_{0}\right) / \mathrm{K}_{0}\right]=\left[\left(\mathrm{A}_{\mathrm{t}}-\mathrm{A}_{0}\right) / \mathrm{A}_{0}+\left(\mathrm{L}_{\mathrm{t}}-\mathrm{L}_{0}\right) / \mathrm{L}_{0}\right]$, and, as a consequence, in the steady state, $Y$ and $K$ and $A L$ all grow by $\left(A_{t}-A_{0}\right) / A_{0}$, i.e., at the initial Hicks rate of "invention neutral” technical change.

As a result, now, letting $n=0$, in addition to $A_{t} L_{t}=L_{0} e^{g t}$, with technical change growing equi-proportionately across capital and labor, $A_{t} K_{0}=K_{0} e^{g t}$, so that $A_{t} L_{0}$ and $A_{t} K_{0}$ grow at the same rate g. In the new equilibrium, Hick’s characterization of Harrod-neutral technical change now applies to the final equilibrium outcome of Hicks neutral change: “...it is the same equilibrium when capital has doubled and everything else has doubled, as it was before.” The change in g leaves the K-Y ratio is unchanged. Hence, with Hicks-neutral technical change, g does not belong in the $\mathrm{V}$-vector. When technical change is factor neutral, the K-Y ratio is simply determined by $\mathrm{s} /(\mathrm{n}+\delta)$. This outcome might lead us to believe that the critical condition determining whether $\mathrm{s}, \delta$, $\mathrm{n}$, or $\mathrm{g}$ belongs in the $\mathrm{V}$ vector is whether the parameter is factorbiased, as is each of these parameters, whereas, by definition, Hicks neutral technical change is entirely factor neutral.

However, as shown in Annex B, regardless of the factor bias of the initial inventive technical change, for the case of $\sigma=1$, the initiating invention technical change "degenerates" to the Harrod state. With a unitary substitution elasticity, the factor income shares remain fixed, so that the effective supplies of all the factors increase equi-proportionately. The increase in K, L, and $\mathrm{Y}$ in equal proportions leaves the $\mathrm{K}-\mathrm{Y}$ ratio unaltered. If this is the case, why do increases in g, measured as Harrod-neutral change lead to declines in the K-Y ratio?

The partial adjustment process: The second condition that we raised in the Overview section above that can explain why a change in $\mathrm{n}$ or $\mathrm{g}$ might affect the $\mathrm{K}-\mathrm{Y}$ ratio is that of the partial adjustment process that can result in time lags in the adjustment of capital relative to labor. We specifically examine population growth, $n$. An increase in $n$, instantaneously affects the physical supply of labor; however, as a result of the commensurate increase in capital's marginal product, increases in the physical supply of capital ensue through the equation of motion with a lag. With an increase in $\mathrm{n}$ or $\mathrm{g}$, the incremental growth in the physical supply of capital never catches up, always lagging behind the accelerated growth in the effective supply of labor resulting from the increase in $\mathrm{n}$ or $\mathrm{g}$.

Let's revisit the consequence of a change in the rate of growth of population, while now assuming that the capital stock adjusts instantaneously to changes in $\mathrm{n}$. We do this by specifying 
the equation of motion such that the capital stock fully depreciates at the end of the last period and is entirely created at the beginning of the current period. That is, $K(t)=(1-\delta) K(t-1)+s Y(t)$ with $\delta=1$, which simplifies to $\mathrm{K}_{\mathrm{t}} / \mathrm{K}_{\mathrm{t}}=\mathrm{sY} / \mathrm{K}_{\mathrm{t}}$, so that:

$$
\mathrm{K}_{\mathrm{t}} / \mathrm{Y}_{\mathrm{t}}=\mathrm{k}_{\mathrm{t}} / \mathrm{y}_{\mathrm{t}}=\mathrm{s}
$$

Eq. (8) represents a "steady state" which adjusts instantaneously to changes in n, such that within a single period L, K, and Y all grow contemporaneously by $1+n$. In this case, in which each of the factors adjusts instantaneously within the system, assuming this “one-hoss shay” form of depreciation, a change in population growth results in contemporaneous, equi-proportional changes in $\mathrm{K}, \mathrm{L}$, and $\mathrm{Y}$.

Applied to g, the above example assumes that technical change is disembodied. As Solow (1960, p. 91) observes: “...many, if not most, innovations need to be embodied in new kinds of durable equipment before they can be made effective.” Nonetheless, the conventional neoclassical growth model assumes that labor-augmenting technical change is disembodied, i.e., as g progresses, the entirety of the workforce upgrades its quality without the investment of human capital or through any other partial adjustment process. In positing our argument that Hicks-neutral technical change is invention and factor neutral, we assume that the inventions are distributed over the range of factors in such a way that they affect the effective supply of every factor symmetrically, so that the effective supplies of K, L, and Y all grow simultaneously and equi-proportionately. One way to do this - the conventional way - is to extend the Harrod assumption by assuming that the technical change is disembodied, so that the entire range of factor inputs instantaneously and simultaneously enjoys the upgrade.

The second method is to assume some form of adjustment process, the most likely being that of vintage of upgrades for capital and labor that are installed through equations of motion that shape the investment dynamic for every factor. The approach, for example, would require two adjustments to a Mankiw-Romer-Weil augmented-Solow-like model: i) the addition of a third investment process relating to physical labor in which, say, heath care upgrades, increased retirement ages, or other factors expand the effective contribution of physical labor, ${ }^{17}$ and ii) a certain harmonization of rates of savings and depreciation, so that the effective supplies of each

\footnotetext{
${ }^{17}$ With labor divided between its skilled and unskilled components, the challenge is to augment the effective supply of unskilled labor without substantially altering its quality, which is presumably the domain of the human capital factor.
} 
of the factors would increase more or less equi-proportionately, through a partial adjustment process, in response to changes in g. ${ }^{18}$

While some mix of embodied and disembodied technical change is more realistic than that of instantaneous, disembodied technical change embraced by the conventional Harrod and Hicks characterizations of technical change, if Hulton's finding (1992) is correct, no more than $20 \%$ of productivity growth in manufacturing has originated with the embodied form. Therefore, accepting the disembodied assumption and having demonstrated that the Hicks-invention-neutral assumption is far more suitable than the steady-state Harrod assumption, g should be omitted form the steady-state condition.

Implications: This conclusion has serious implications for neoclassical growth theory. One immediate implication of dropping g from the steady-state equation is to eliminate an awkward feature of the conventional growth model specification. Having $g$ in the steady state equation renders the whole neoclassical system difficult to implement or interpret empirically.

A more important reason is that aspects of its inclusion in the steady-state equation with reasonable parameter values yield counter-intuitive results. Annex $\mathrm{C}$ demonstrates The Purgatory Paradox, the condition that by virtue of its inclusion in the steady state equation, an increase in g, measured in the conventional Harrod manner, results in a decline in the capitaloutput ratio. According to the examples in Annex C, this increase in the rate of technical change, generally viewed as unambiguously good, has a devastating transitional effect. As shown in Annex C, because the increase in g leads to a decline in the K-Y ratio, a precipitous decline in the growth of output per capita and living standards may also ensue.

This expanded role of Hicks-neutral technical change further recommends that more attention be given to ways in which factors other than physical capital are augmented through technical change. With embodied technical change, the parameters $\mathrm{s}, \delta$, and $\mathrm{n}$, as well as $\mathrm{g}$, are all implicated in the dynamic process of the absorption and diffusion of new vintages of technology. These are likely to affect factor intensities relating to various types of physical and human capital in different ways. From a research and policy perspective, these insights underscore the need to give more serious attention to the current incomplete and misleading measures of rates of savings and depreciation across a range of physical and human inputs in

\footnotetext{
${ }^{18}$ One economic interpretation that might support the assumption of symmetric technology adjustment across factors is that with $\sigma=1$, viewed as an elasticity of complementarity, technology upgrades to computers, software, and programmers are required to be integrated and choreographed.
} 
most national income accounts. Whether the focus is on physical capital, human capital, or unskilled labor, each embodies significant degrees of savings, investment, and depreciation. ${ }^{19}$ The Purgatory Paradox in Annex C underscores the importance of more deeply understanding the transitional impacts of changes in the included steady-state parameters. The following section illustrates how the levels of these various elements of the V-vector can wield a much greater impact than one-time changes that have only transitory impacts on the growth of living standards. We show how the levels of $\mathrm{s}, \delta$, and $\mathrm{n}$ can fundamentally affect the rate of growth of living standards within the steady state, including accounting for significant turning points in historic rates of growth that may propel or stall nations in their quest for prosperity.

\section{The Technology Multiplier}

Perhaps the most critical reason why the conventional textbook characterization of economic growth begs for correction is that the choice of Hicks- vs. Harrod-neutral technical change fundamentally alters the account of the neoclassical growth process. The choice of production technology, whether of the Hicks variety, $Y=(A K)^{\alpha}(A L)^{1-\alpha}$, or the Harrod variety, $Y$ $=\mathrm{K}^{\alpha}(\mathrm{AL})^{1-\alpha}$, results in strikingly different specifications of the balanced growth equation. We demonstrated this in Section 2 with the contrast between Eqs. (4) and (6):

$$
\begin{aligned}
& \mathrm{y}^{\wedge}=[1 /(1-\alpha)] \mathrm{A}+[\alpha /(1-\alpha)] \mathrm{V}^{\wedge} \\
& \mathrm{y}^{\wedge}=\mathrm{A}+[\alpha /(1-\alpha)] \mathrm{V}^{\wedge}
\end{aligned}
$$

The sole difference between (4) and (6) is the magnitude of the technology multiplier, which, as referenced in Section 2 lies in the range of 1 to $\infty$ for the Hicks case, shown in Eq. (4), while, as shown in Eq. (6), it is constrained to unity for the Harrod case.

One consequence of the limiting effect of the Harrod assumption is unintentionally demonstrated by Mankiw, Romer, and Weil (1992) in which they expand the scope of capital and thereby increase the magnitude of total capital's output elasticity, which in turn reduces the severity of diminishing returns to investment. Their Eq. (11), reproduced below, shows that by adding savings and investment in human capital, the combination of the additional human capital

\footnotetext{
${ }^{19}$ Possibly no country other than China publishes an official or quasi-official annual report on the creation and use of human capital across its economy: Human Capital in China, 2015, China Center for Human Capital and Labor Market Research, Central University of Finance and Economics, Beijing.
} 
output elasticity $(\beta=1 / 3)$ with the pre-existing physical capital elasticity $(\alpha=1 / 3)$ increases total capital's elasticity to 2/3. As shown in Eq. (11), the greater the magnitude of $\alpha+\beta$, the larger the multiplier effects on $\mathrm{Y} / \mathrm{L}$ for the savings rates $\mathrm{s}_{\mathrm{k}}$ and $\mathrm{s}_{\mathrm{h}}$ for physical and human capital respectively. What MRW do not acknowledge is that regardless of whether human capital is included or not, the multiplier effect of technical change (g) remains confined to unity.

$$
\text { (11) } \begin{aligned}
\ln \left[\frac{Y(t)}{L(t)}\right]=\ln A(0)+ & g t-\frac{\alpha+\beta}{1-\alpha-\beta} \ln (n+g+\delta) \\
& +\frac{\alpha}{1-\alpha-\beta} \ln \left(s_{k}\right)+\frac{\beta}{1-\alpha-\beta} \ln \left(s_{h}\right) .
\end{aligned}
$$

Therefore, whereas with the addition of human capital, values of $\mathrm{s}_{\mathrm{k}}$ and $\mathrm{s}_{\mathrm{h}}$ augment the level of $\mathrm{Y}(\mathrm{t}) / \mathrm{L}(\mathrm{t})$, it does nothing to affect the steady state rate of growth of living standards. This is a puzzle: If an increase in capital's elasticity reduces the severity of diminishing returns to investment so as to magnify the impact of an increase in the savings rate on living standards, why cannot the same increases in capital's elasticity enable successive increases in A (i.e., g), which increase both savings and investment, to also multiply their impacts? ${ }^{20}$

As shown in Eq. (4), only when the production technology is of the Hicks variety does the addition of human capital enable an increase in g to diffuse through the economy so as to more greatly expand output per capita. Under the prevailing assumption of Harrod-neutral technical change, regardless of whether capital's output elasticity is $1 / 3$ or $2 / 3$, a $10 \%$ increase in $\mathrm{A} \wedge$ translates to just a $10 \%$ increase in output per worker. For the Hick’s case, for a total elasticity of $1 / 3$, the $10 \%$ increase in $\mathrm{A}^{\wedge}$ results in a $15 \%$ increase in the rate of growth of output per worker; for the larger total capital elasticity of $2 / 3$, the same increase in $A^{\wedge}$ results in a $30 \%$ increase in the rate of growth of living standards. This difference in the technology multipliers is shown in Fig. 3, which shows how as $\alpha$ increases, $\mathrm{A}^{\wedge}$ transforms into faster rates of growth of $\mathrm{y}^{\wedge}$.

One way conceptually to think of the ways in which the technology multiplier operates is to apply the simple concept underlying Romer’s (1986) and Lucas’ (1988) externalities version

\footnotetext{
${ }^{20}$ Of course, the answer is that as $\alpha$ increases, $\mathrm{g}$ 's direct impact (1- $\alpha$ ) diminishes, thereby offsetting the larger impact effect, i.e. $\alpha$, of the enlarged capital elasticity, so that the total elasticity remains constrained to unity. The implication is that the window for genuine technology augmenting technical change becomes increasingly narrow, i.e., $1-\alpha$, as the burden of the requirement for the accumulation of complementary primitive capital grows.
} 
of technical change, resulting respectively from agglomerations of physical and human capital. Romer, for example, assumes that $\mathrm{A}(\mathrm{t})=\mathrm{BK}(\mathrm{t})$, so that the knowledge stock of the economy is proportional to the capital stock. According to Acemoglu's interpretation (2009, p. 399), for the physical stock of capital, “This assumption can be motivated by 'learning-by-doing,” whereby the greater investments in certain sectors increase the experience (of firms, workers, and managers) in the production process, making the production process itself more productive.” Spillovers from human capital extend back to Nelson and Phelps (1966) and Schultz (1975). Again, as summarized by Acemoglu (2009, p. 310), “According to this perspective, the major role of human capital is not to increase productivity in existing tasks, but to enable workers to cope with change, disruptions, and especially new technologies.” That is to say, with the accumulation of agglomerations of capital - both physical and human - economies, both more and less developed, acquire certain capabilities, enabling the clustering and interaction of varieties of capital to spawn new ideas and methods. ${ }^{21}$ In this sense, $\alpha$ is a kind of "standing on shoulders of giants” parameter; it enables major global innovations to diffuse and multiply through the accumulation of a multitude of minor, local incremental innovations. ${ }^{22}$

The relative importance of $\mathrm{A}^{\wedge}$ and $\alpha$ can be formally shown by taking the total derivative of $[1 /(1-\alpha)] \mathrm{A}^{\wedge}$ with respect to $\mathrm{y}^{\wedge}$ :

$$
\mathrm{dy}^{\wedge}=\mathrm{A}^{\wedge}\left[1 /\left(\alpha^{\prime}-1\right)^{2}\right] \mathrm{d} \alpha+[1 /(1-\alpha)] \mathrm{dA}^{\wedge}
$$

where $\alpha^{\prime}=$ the mean of the initial and substitute values of $\alpha$, i.e., $(\alpha+(\alpha+\mathrm{d} \alpha)) / 2$. Thus, for example, if a developing country were to raise its capital share - the sum of its physical and human capital intensities - from $1 / 3$ to $1 / 2$ and then from $1 / 2$ to $2 / 3$, given a rate of technology advance of $2 \%$, the country would succeed in increasing its own rate of growth of income per capita from an initial rate of $3 \%$ to $4 \%$ and then with the subsequent capital deepening from $4 \%$ to $6 \% .{ }^{23}$ Although both increments are $1 / 6$, we see the condition of increasing returns to the rising capital intensity in which the same increment of 1/6 raises the home rate of advance by just 33\% initially and then subsequently by 50\%. This increasing multiplier effect results from

\footnotetext{
${ }^{21}$ The introduction of the technology multiplier has a range of policy implications, including that of developing economies limiting tariffs on imports of intermediate and capital goods. See Romer (1994a).

${ }^{22}$ Another way to think about the multiplier effect is that a X\% increase in the stock of patents may translate into a $[1 /(1-\alpha)] X \%$ increase in living standards.

${ }^{23}$ Note that the accuracy of the computation increases as $d \alpha \rightarrow 0$. In principle, the slope represented by Eq. (9) holds only for a single point along the function $f(x)$.
} 
technical change spilling across increasingly large portions of the economy through increases in the effective supply of the complementary inputs to physical labor relative to the increasingly narrow base of a fixed labor force.

These results carry potentially profound implications for our understanding of the nature of technical change. Much has been written about the failings of Solow's basic model to account for differences in living standards across more developed and less developed economies. ${ }^{24}$ With our model set up, economies may confront an exogenously-given, relatively uniform rate of technical change. However, differences in the role of capital in their economies (i.e, their $\alpha$ values) may result in disparate abilities to access and absorb benefits from the exogenous technology. With heterogeneous technology multipliers, substantial differences in incomes may be consistent with a globally uniform rate of growth of non-excludable, non-rivalrous technical change. Moreover, once we acknowledge the operation of the technology multiplier, we can better understand the phenomena of explosive growth and catch-up as demonstrated by Asia's so-called Four Tigers during the latter half of the Twentieth Century, as well as China's growth surge over recent decades.

Thus the limiting factor in Solow's basic model may not have been its failure to differentiate exogenously-given rates of technical change. Rather, the key factor that failed to account for differences in cross-country living standards may have been the ill-advised marriage combining Harrod-neutral technical change with the assumption of uniform factor weights and production technologies - uniform both across countries and across time. ${ }^{25}$

Frontier versus catch-up technical change. The process of technical change for the frontier, OECD countries is quite straightforward, i.e., $\mathrm{A}_{2}{ }^{* \wedge}=[1 /(1-\alpha)] \mathrm{A}_{1}{ }^{* \wedge}$, where $\mathrm{A}_{1}{ }^{* \wedge}$ and $\mathrm{A}_{2} * \wedge$ respectively represent Hicks and Harrod-neutral technical change within the frontier country. The question is whether technical change for the catch-up developing countries should be understood and characterized in a different way. The answer is "yes.”

For all countries, the technology multiplier measures the capacity of an economy to transform its initial encounter with technologies that are new to their economies into functioning

\footnotetext{
${ }^{24}$ See, for example, Romer (1994).

${ }^{25}$ This is not to suggest that capital and labor's factor income shares are substantially changing contrary to Kaldor's stylized facts; rather, the observed changes in factor shares are largely within the broad categories of capital and labor; in particular, a stylized fact of the development process is that human capital commands increasingly large shares of total labor's relatively constant income share.
} 
operating systems that effectively utilize the technologies to improve living standards. This is the generic definition of the technology multiplier.

Succinctly put, the challenge for frontier countries is converting Hicks' invention-neutral technical change, i.e., novel, useful innovations, into labor-augmenting Harrod-neutral technical progress. After the Harrod technical progress has materialized in the frontier countries, having driven capital's marginal product and the returns to capital back to their historic levels, the challenge of the catch-up economies is to then transfer the accessible Harrod technology in the frontier countries, now widely embedded in capital, to Harrod technologies in the catch-up economies. $^{26}$

For frontier countries, the technology multiplier measures the extent to which it can transform Hicks invention neutrality into Harrod-neutral technology advance. Inventors and investors face a high-degree of risk; early adopters face relatively high costs and uncertainty. Only after the invention-neutral innovations have been installed, utilized, and refined through learning-by-doing and learning-by-using has their potential become fully embedded in Harrodneutral technology, otherwise knowable as “mature Hicks-neutral technology.”

For catch-up economies, the relevant technologies have become embedded in readily available forms of capital that can be replicated in the factory, on-line and in the sales room, and in the classroom. The challenge facing catch-up countries is to access and absorb the mature Hicks-frontier Harrod state of the world, i.e., $\mathrm{A}_{2}{ }^{*}$, into an indigenous Harrod technology. As a result of the embeddedness and frontier learning that has converted inventions into readily available and transferable physical and human capital, for the catch-up economies, the spread between the marginal cost and benefit of these technologies is potentially much greater than when they were still in their Hicksian stages of development at the global innovation frontier. Although in the frontier economies, capital deepening has driven down the MPK to its historic levels, for the catch-up economies, this process of capital deepening has elevated the potential marginal product of the new forms of physical and human capital to levels above what they had initially been in the frontier economies, holding fixed the original factor intensities. That is, given sufficient levels of $\alpha$ in the catch-up economy, the introduction of an established, now refined transportation, communication, or manufacturing technology can be more impactful than

\footnotetext{
${ }^{26}$ As shown in Fig. B-1, the Hicks-neutral technology, having once been become to Harrod-neutral, may also be characterized as "mature Hicks-neutral technology."
} 
it had been in a frontier economy. This spread is further magnified when these newer technologies are replacing or effectively complementing older technologies, as with the first-time introduction of computers into a business or classroom, as compared with routine 3-year upgrades of existing stocks of computers in frontier countries. These are the "advantages of backwardness" - the potential for high impact, low cost technology transfer - as elaborated by Gershenkron (1962).

Given this distinction, for catch-up countries, the technology multiplier $1 /(1-\alpha)$ has a somewhat different interpretation than it has for the frontier countries. For frontier countries, the technology multiplier measures the capacity of an economy to convert Hicks invention-neutral technical change into Harrod technical progress involving higher living standards. For catch-up countries, the multiplier represents the capacity of a country to transform frontier-country Harrod technical change $\left(A_{2} * \wedge\right)$, to host-country Harrod technical change $\left(A_{2} \wedge\right)$. Wherever the technology multiplier results in $\mathrm{y}^{\wedge}=\mathrm{A}_{2} \wedge>\mathrm{A}_{2} * \wedge$, ceteris paribus, a convergence of living standards can materialize for catch-up countries. In effect, for the catch-up economies, frontier country Hicks invention-neutral technical change becomes catch-up Harrod-neutral living standards through the following two-stage multiplier process:

$$
\mathrm{A}_{2} \wedge=[1 /(1-\alpha)]^{*}\left[1 /\left(1-\alpha^{*}\right)\right] \mathrm{A}_{1} * \wedge
$$

These economies benefit from receiving the already processed, tried and tested, embodied technologies, which they then convert to domestic labor-augmenting technical change.

For catch-up countries, larger K-Y ratios and larger values of $\alpha$ can have opposing effects, On the one hand, larger $\alpha$ 's represent an established capacity to effectively transfer technology and achieve steady-state Harrod gains. The more physical and human capital they already have in place, the greater the capabilities of catch-up countries to access, adapt, and absorb these technologies. On the other hand, a larger $\alpha$, particularly if it is stocked with vintages of frontier capital, may be associated with less backwardness ${ }^{27}$ - a crimped technology gap - and less capacity for increases in $\alpha$ that, at earlier levels of development, may have substantially

\footnotetext{
${ }^{27}$ This image reminds the author of visiting factories in China during the 1980s for which the entryways were often lined with crates of new unpacked equipment, often imported state-of-the art equipment. Factory managers explained that they simply did not have the know-how to install or maintain the new vintages of equipment.
} 
accelerated rates of growth of $\mathrm{y}^{\wedge} .^{28}$ Econometric specifications and methods will need to attend to separating the relative significance of the within multiplier versus the cross-sectional country catch-up effects.

In the next section, we investigate the implications of the above discussion for the endogenous growth literature and future directions in understanding the drivers of economic growth.

\section{Implications for Endogenous Growth}

Endogenous growth theory has been a logical, necessary, and welcome extension of neoclassical growth theory. Acemoglu (2009, Ch. 15) shows that for endogenous growth models, as well as for models with exogenous technical change, the balanced growth path requires technology to be of the labor-augmenting variety. Key insights of this paper - that technical change can be of the Hicks-Harrod form and that its measure, g, does not belong in the steady state equation - also hold when the neoclassical growth system is embedded with models of endogenous growth. We first examine how the plausibility of various modelling strategies of the endogenous innovation literature have been impaired by the prevailing assumption that technological change is "purely labor-augmenting."

Problems for the current literature. The existing literature largely consists of two streams: that which focuses on deliberate allocations of resources at the firm level for the purpose of innovation and that which models ways in which agglomerations of capital generate unintended externalities or spillovers within certain geographic and/or technology neighborhoods. Each of these modeling strategies, in turn, has two objectives: first, to identify plausible processes for creating and/or transferring new technologies; the second, as a by-product of the first, is to expand the role and elasticity of total capital so as to reduce the severity of diminishing returns.

The shortcomings of this literature can perhaps be best described by highlighting its internal inconsistencies and dilemmas. We discuss these below:

1. Earlier sections of this paper have given adequate attention to the nonsensical nature of “purely labor-augmenting technical change” as a description of the growth process separate from its emergence in the final steady-state equilibrium. By focusing on this narrow slice of

\footnotetext{
${ }^{28}$ That is, such countries may be encountering the challenges sometimes associated with the Middle Income Trap in which the salient challenges may have more to do with institutional deficiencies rather than technology backwardness.
} 
the growth process, the standard growth theory evades or distorts essential features of a rich dynamic, in which new ideas and methods are created, embedded in multifarious forms of capital, accumulated and dispersed throughout economies, and, finally, having been absorbed into a steady state, augment the wealth and living standards of nations. Where the endogenous growth literature focuses on these important elements of the growth process, it essentially tells a story about the use of capital - physical, human, and intellectual - to innovate novel and more technologically advanced versions of itself, a story that is inconsistent with a core tenet of the neoclassical growth literature. Harrod-neutral technical change can occupy a place in the growth story, but it does nothing to inform the growth process and comes into existence only as the last chapter in the story of economic growth after the initial Hicks "invention neutrality" has entered and strutted across the stage before transforming to the Harrod condition, having itself created the conditions for its eventual submission - and misinterpretation. In short, growth theory does itself an enormous disservice with its singular focus on the steady state.

2. Much of endogenous growth theory is inconsistent with the tenets of neoclassical growth theory and with the stylized facts of long-term growth. Indeed, one of the implications of having mistakenly embedded the basic Solow model with the Harrod-neutral production technology is that a significant number of papers have found the Harrod-neutral assumption to be inconvenient, inconsistent, or unintuitive and have thus consciously or unconsciously abandoned the assumption of Harrod neutrality. ${ }^{29}$ Having foregone the conventional steady-state condition, many papers likewise seemingly abandon any attempt to adhere to the stylized facts of balanced growth. In Table 1, we identify a number of notable contributions to endogenous growth theory, of which some have retained the purely laboraugmenting assumption, while numerous others have altered or ignored it.

3. As shown in Annex C, by reducing the K-Y ratio, increases in $g$ of the Harrod variety have unwelcome implications for the economy's economic transition. This is paradoxical, since endogenous growth theory seeks to accelerate g, the pace of technical change. In the case

\footnotetext{
${ }^{29}$ One example of this is the class of AK models. That AK models have developed into a serious stream of endogenous growth theory is an illustration of the disconnection that can exist between neoclassical growth theory and follow-on efforts to generate sustainable growth. Rebelo's model (1991) with both physical and human capital, for example, omits unskilled labor altogether. In doing so, this model effectively adopts the assumption of Hicks- neutral technical change in which all of the included factors grow at a constant rate, g. Its omission of physical labor violates the Inada Conditions, a cornerstone of neoclassical economics.
} 
of the MRW model, increases in g act to reduce the intensity of both physical and human capital in the labor force, i.e., the ratios $\mathrm{K}-\mathrm{Y}$ and $\mathrm{H}-\mathrm{Y}$ both fall, thus increasing the economy's unskilled factor income share. That an acceleration of endogenously-generated technical change should be associated with reductions in an economy's physical and human capital ratios, while the factor income share of unskilled labor increases, is fundamentally inconsistent with the stylized facts of every country that has experienced economic advance in recent decades. No models of the welfare- or profit-maximizing advantages of endogenous technical change take into account the disruptive transitional impacts that they encounter as shown in Annex C. Moreover, if they were to account for these impacts, depending on social discount rates, such disruptive effects may well dissuade countries from encouraging efforts to accelerate the pace of technical change.

4. The source of technical change, fundamental to the original Solow model, is ambiguous. The current consensus is that Solow had intended for technical change to be an exogenously-determined public good. Because, within the Harrod context, a uniform rate of exogenous technical change is unable to account for the large observed disparities in national incomes, this view has been dismissed. As a result, there is now no clear distinction in the neoclassical literature between the creation and diffusion of technical change as a public good, potentially assessable by all firms and all economies, and the conditions that are specific to each economy that determine its independent ability to absorb the world's generally available technologies. By not clearly distinguishing between the processes and challenges of growth for the full range of developed and developing economies, the model has limited connection and policy prescription for the field of development economics.

5. Established growth theory may be excessively focused on the steady state with insufficient attention on the episodes involving growth take off and periods of relative stagnation or decline that may do far more to define the economic condition of nations than the idealized phenomenon of "balanced growth" and the "steady state.” Reversals in rates of savings and population combined with or interacting with changes in capital's total elasticity, i.e., the technology multiplier, may be critical for understanding growth surges and stagnation rather than simply being accorded the conventional second order effects on transitory changes in the K-Y ratio and minor level adjustments. 
These five inconsistencies with the most fundamental stylized facts of modern economic growth are each reasons for Solow to characterize the notion of labor-augmented technology in production as "fanciful" and for Acemoglu to find it "distressing."

In the following section, we sketch out an alternative vision for the endogenous growth agenda.

A vision of endogenous growth. The problems associated with shortcomings \#1 - \#3 should be resolved by the adoption of the integrated Hicks-Harrod paradigm and its elaborations as described in previous sections. The following brief summary of the frontier-catch-up country distinction sketched in the previous section addresses Shortcoming \#4. In order to address Shortcoming \#5, the next sub-section explores the matter of using the tools of neoclassical growth analysis to study deviations from balanced growth.

1. Frontier technical change, $A * \wedge$ : Outward shifts in the global technology frontier result from the collection of deliberate innovation activity among individual innovators, primarily those engaged with OECD-centered innovation. For the rest of the world, once these innovations have become embedded in physical and human capital, they transform to exogenous, public-good technologies available for imitation and absorption. Technical change accumulating at the global frontier, represented as Hicks' invention neutral change, drives the potential global invention and production frontier. This dynamic has been captured in models, including Romer (1990) and Jones and Vollrath (2013), in which the number of persons involved in the invention process and the tension between the "standing on shoulders" and "fishing out" phenomena determine A*^. A popular measure of $\mathrm{A}^{* \wedge}$ is quality patent production. ${ }^{30}$

2. Catch-up technical change: The process of technical change in developing economies is distinctly different than in frontier economies. The difference is as different as between innovation and replication. As shown in Eq. (10), catch-up technical change is the second stage of a two-stage process. Once the frontier sector has created and embodied new technologies, i.e., $\mathrm{A}_{1}{ }^{* \wedge} \rightarrow \mathrm{A}_{2}{ }^{* \wedge}$, with this pre-condition catch-up economies are able to create a bridge to higher domestic living standards, i.e., $A_{2}{ }^{* \wedge} \rightarrow A_{2} \wedge$. For both set of

\footnotetext{
${ }^{30}$ The quality condition needs to account for the likelihood that some portion of the recent surge in global patenting has been driven by spurious elements, including strategic patenting. See Jaffe and Lerner (2007).
} 
countries the bridges are embedded in $\alpha$, the weight of total capital - physical and human - in their economies.

The essential point relating to the magnitude of $\alpha$ is not that it by itself generates new ideas and patents, rather that countries with large and growing $\alpha$ 's capture and generate spillovers with greater effect than if the new ideas were simply exogenously installed in every workshop in the absence of copious physical and human capital. Such spillovers have been readily represented by Arrow (1962), Romer (1986, Lucas (1988), and others. These studies, however, have not included a method of formally distinguishing between the public good element of technical change and the capabilities of individual countries to capture the spillovers from the public good $A_{2} * \wedge$. The distinction in Eq. (4) between $\mathrm{A}^{\wedge}$ and the technology multiplier, $1 /(1-\alpha)$, enables that differentiation.

Deviations from balanced growth - takeoff and stagnation. Here we attempt to address Shortcoming \#5. Arguably, most countries that transition from low-income status to middleincome status and then from middle to high-income status experience surges in their growth rates that exceed those that are sustainable for long periods along a balanced growth path. In showing that a small increase in Harrod-style technical change can dramatically depress a country’s growth path, Annex $\mathrm{C}$ can also be used to show the impact of small changes in the parameters that, in fact, belong in the steady-state condition: $\mathrm{s}, \mathrm{n}$, or $\delta$.

Let's examine the effect of an increase in the savings rate and thereby turn the Purgatory Paradox on its head. Fixing the parameter values for s and $\delta$ each at $10 \%$ and setting the rate of population growth to $2 \%$, we use the set up in Annex $\mathrm{C}$ to analyze the impact of an increase in the savings rate from $10 \%$ to $15 \%$, a $50 \%$ increase. ${ }^{31}$ This increase in s results in a $41.7 \%$ increase in the K-Y ratio. Using Eq. 6, for $\alpha=1 / 3$, this increase, in turn, translates into a cumulative $20.8 \%$ increase in $\mathrm{y}^{\wedge}$ extending over the transition period. For a 10 -year transition from the lower to the higher K-Y ratios, the increase in the savings rate implies an annual increase in $\mathrm{y}^{\wedge}$ of $1.9 \%$ as the economy transitions from one steady state to the next.

\footnotetext{
${ }^{31}$ In accord with our finding in Section 4 that as a measure of Hick-neutral technical change, $g$ should be omitted from the steady-state equation, this exercise excludes $\mathrm{g}$ from the factors determining the K-Y ratio.
} 
Thus far we have analyzed changes in $\alpha$ and $V$ as if they were unrelated. In fact, capital's output elasticity consists of two components, capital's marginal product and the capital-output ratio, i.e., $\alpha=(\mathrm{dY} / \mathrm{dK})(\mathrm{K} / \mathrm{Y})$. That is,

$$
\alpha=\mathrm{rV},
$$

where $r$ is the rate of return on capital and $V=K / Y=s /(n+\delta)$ as redefined in the previous section. Eq. (11) relates Kaldor's three central stylized facts of growth: a fixed capital-output ratio, V, a stable return on capital, $r$, and constant factor income shares, $\alpha$ and 1- $\alpha$. A deviation in any one of these conditions must dislodge at least one other condition. Once, we account for this link between $\alpha$ and V, our analysis fundamentally changes. Given that $\alpha=r V$, and accepting Kaldor's stylized fact of fixed returns to capital (i.e., $\mathrm{r}^{\wedge}=0$ ) implies that $\alpha^{\wedge}=\mathrm{V}^{\wedge 32}$. Thus, any change in $\mathrm{V}$, say resulting from a change in s, $\mathrm{n}$ or $\delta$ in the steady-state equation, will also change $\alpha$ and the technology multiplier.

Continuing our analysis of the impact of the impact of a rise in the savings rate from $10 \%$ to $15 \%$, in step with the change in the $\mathrm{K}-\mathrm{Y}$ ratio, $\alpha$ also rises by $41.7 \%$. This increase translates to an increase in $\alpha$ from the initial $1 / 3$ to 0.472 , causing the technology multiplier to rise from 1.5 to 1.9. As a result, when the economy reaches its new steady state, $\mathrm{y}^{\wedge}$ settles down at $3.8 \%$. Hence, the rise in the savings rate from $10 \%$ to $15 \%$ results in nearly a one percent increase in the steady state rate of growth of output per capita. Furthermore, during the transition, as it accelerates toward its steady state growth rate, the economy also receives an additional growth surge of nearly $2 \%$ as it bumps up to a higher K-Y ratio.

China's surge in gross national savings from approximately 35\% in 1999 to 52\% in 2007 replicates the 50\% rise in savings in the simulation exercise described above. This savings surge may well have contributed to the country's sustained rates of $8-10 \%$ annual rises in output per capita, notwithstanding a considerable contemporaneous narrowing of its technology gap with the rest of the world. Apart from cyclical conditions, the falloff in savings rates after 2007-08

\footnotetext{
${ }^{32}$ As it would be in a small, open economy with a high degree of capital mobility.
} 
combined with the continued closing of the technology gap are likely to have set the stage for China's post-2010 decline in potential output growth. ${ }^{33}$

For the N. American and W. European countries, as much as the acceleration of technical change is likely to have contributed to their post-WWII growth surge, the dynamic interaction of changes in $\alpha, \mathrm{s}$ and $\mathrm{n}$ may have been equally important for driving the take-off stage of growth experienced by the founding OECD countries during the late 1940s to early 1970s. ${ }^{34}$ Other examples of growth surges include S. Korea from the early 1960s through 1980, and Japan in the 1950s and 1960s. ${ }^{35}$ Notable slowdowns include the U.S. in the 1970s, Japan in the 1980s, and countries that currently reside in the so-called middle-income trap. A relevant growth model should be able to provide insight and the ability to calibrate the nature of the turning points associated with these critical growth discontinuities.

Combining Eq. (11) and the corrected Solow steady-state condition, capital's output elasticity is exogenously determined as follows:

$$
\alpha=\mathrm{rs} /(\mathrm{n}+\delta)
$$

Substituting (12) into (4) and solving for the steady state $\mathrm{y}^{\wedge}$ gives:

$$
\mathrm{y}^{\wedge}=[1 /(1-\mathrm{rs} /(\mathrm{n}+\delta))] \mathrm{A}^{\wedge}+[\mathrm{rs} /(\mathrm{n}+\delta)] /\left(1-[\mathrm{rs} /(\mathrm{n}+\delta)]\left(\mathrm{s} /(\mathrm{n}+\delta)^{\wedge}\right.\right.
$$

Eq. (13) shows that the elements of $\alpha$ - notably the rates of savings, population growth, and depreciation - play a far more central role in driving the rate of growth of output per capita than heretofore acknowledged in either the basic neoclassical growth theory or endogenous growth theory. We see that changes in the rate of savings not only alter the balanced growth path with

\footnotetext{
${ }^{33}$ Clearly, deviations from the BGP matter for counties that surge into the Middle Income Trap or that seek to escape it. Eichengreeen et al (2011) report their finding that rapidly growing economies slow down significantly, in the sense that the growth rate downshifts by at least 2 percentage points, when their per capita incomes reach around $\$ 17,000$ US in year-2005 constant international prices.

${ }^{34}$ Gao and Jefferson (2007), for example, document the phenomenon of the Science and Technology (S\&T) Takeoff, in which virtually all of the world's larger high-income countries have experienced surges in their R\&D intensities the ratio of R\&D spending to GDP - from less than one percent to more than two percent. Remarkably, the authors find that such surges, on average, materialize within a decade, even as the underlying rates of GDP are themselves accelerating. This surge in R\&D intensity is likely to be associated with substantial human capital deepening, particularly in higher education and in the workplace, thus further expanding capital's weight in the overall economy.

${ }^{35}$ Over the 23 years from 1950 to 1973, Japan's gross national product expanded by an average annual rate of more than 10 per cent with only a few minor downturns. From 1962 to 1989, South Korea's real gross domestic product expanded by an average of more than 8 percent per year.
} 
transitory impacts on the K-Y ratio and rate of growth, we also see that the stationary level of the rate of savings determines the size of the technology multiplier and therefore affects the steadystate rate of growth of living standards. ${ }^{36}$ Hence, by affecting capital's output elasticity, the savings rate and the rates of population growth and depreciation - and the return on investment exercise a far deeper impact on economic growth than acknowledged in the conventional neoclassical model of growth.

In conclusion, this section demonstrates several important results: i) endogenous growth modeling needs to distinguish between frontier country technical change and endogenous growth and the nature of technical change for catch-up economies; ii) deviations from the balanced growth path are likely to provide more insight than steady-state analysis for understanding the phenomena of both the takeoff and stagnation of economic growth; (iii) because they determine the K-Y ratio, $\alpha$, and the technology multiplier, the stationary levels of s, $\mathrm{n}$ and $\delta$, fundamentally impact the steady-state rate of growth of output per capita; and (iv), by creating changes in the $\mathrm{K}-\mathrm{Y}$ ratio, $\alpha$, and the technology multiplier, changes in $\mathrm{s}, \mathrm{n}$ and $\delta$, can dramatically deflect economies from their balanced growth paths, accounting for growth takeoffs, stagnation, and capture by the so-called Middle-Income Trap.

\section{Reconciling growth theory and growth accounting}

The proposed revisions and extensions to growth theory described above move growth theory along a path so that it can plausibly partner with the objectives and methods of growth accounting to form a consistent and unified approach to understanding, analyzing, and measuring the growth experience. Specifically, the alterations to growth theory and growth accounting are of two types.

Arguably, the single most important alteration is the recognition that as a theory concerning the creation, diffusion, and persistence of technical change and growth, growth theory needs to frame its analytical structure in accord with the Hicks-Harrod paradigm described in Section 3. By characterizing the initial stage of the growth process, i.e., Hicks' invention neutrality, Eqs. (3) and (4) suitably frame the story of how technical change motivates

\footnotetext{
${ }^{36}$ Note in Mankiw, Romer, and Weil's Eq. (11) that since an increase in $s_{k}$ and an increase in $s_{h}$ would, through their respective steady state conditions, result in increases in $\mathrm{K}-\mathrm{Y}$ and $\mathrm{H}-\mathrm{Y}$, with likely increases in $\alpha$ and $\beta$, the general equilibrium effect of increases in $s_{k}$ and $s_{h}$ would be larger than those implied by the MRW model.
} 
the economic system to absorb and adapt to more efficient vintages of capital and labor. By comparison, growth accounting is, in fact, an accounting method that seeks to compare two already empirically-evolved states of the world. From a growth theoretic perspective, the beginning and end year of the comparison plausibly qualifies as a steady- or quasi-steady state condition. In accord with Kaldor's stylized facts of growth, with only labor's marginal product having risen while the returns to capital have been driven back toward their historic levels, the contribution of technology characterized in the growth accounting exercise can, at last, be suitably calibrated using the metric of Harrod-neutral steady-state technical change.

This proposition poses a striking irony in the established field of growth analysis. Over the past 60 years, since Solow’s 1956 publication, while growth theorists should have been grounding their theoretical analysis in Hicks-neutral technical change, not the Harrod alternative; growth accountants, by contrast, should have been framing their empirical analysis in a Harrodneutral framework, not the Hicks framework. Growth analysis has inverted the logical sequence of the representation of technical change. Henceforth, for the purpose of analyzing growth, we distinguish between the production function, which specifies ex ante production and innovation possibilities versus the accounting function, which identifies and accounts for observed ex post innovation and production steady-state outcomes.

The production function incorporates Hick-neutral technical change; the accounting function incorporates Harrod-neutrality. In fact, the logic used by Uzawa (1961) to conclude that Harrod-neutral technical change is necessary to characterize the steady state is entirely relevant to the Harrod accounting function; it is not suitable for characterizing the production possibilities embedded in a production function. Arguably, over the decades, growth theorists have been conducting an accounting analysis of growth rather than uncovering the deeper dynamics of the growth process.

The second necessary alteration required for the reconciliation of growth theory and growth accounting follows from the first. That is, acceptance within the growth accounting tradition that capital accumulation is first and foremost an endogenous phenomenon. ${ }^{37}$ From an accounting perspective or a "sources of growth" perspective, credit should be given where credit is due. If the economy has experienced substantial capital deepening, given the power of the

\footnotetext{
${ }^{37}$ This critique of growth accounting is not novel; nonetheless, it is generally ignored (as it has been in this author's own work).
} 
neoclassical model, unless the source of the investment and capital deepening can be attributed to exogenous conditions, such as a substantial rise in the savings rate or other factors that are independent of technical change, the default attribution should be technical change.

Let's clarify the arithmetic link between neoclassical growth theory and growth accounting, The central proposition of this paper is that the appropriate specification for the neoclassical growth model is shown in Eq. 4, i.e.,

$$
\mathrm{y}^{* \wedge}=[1 /(1-\alpha)] \mathrm{A}_{1}^{\wedge}+[\alpha /(1-\alpha)] \mathrm{V}^{\wedge}
$$

where $A_{1} \wedge$ is a measure of Hicks-neutral technical change. The link with the standard approach to growth accounting can be made through the following steps. The standard growth accounting exercise starts with the Hicks version of a Cobb-Douglas production function:

$$
\mathrm{Y}=\mathrm{A}_{1} \mathrm{~K}^{\alpha} \mathrm{L}^{1-\alpha}
$$

which can then be converted to a rate of change version:

$$
\mathrm{Y}^{\wedge}=\mathrm{A}_{1} \wedge+\alpha \mathrm{K}^{\wedge}+(1-\alpha) \mathrm{L}^{\wedge}
$$

Rearranging:

$$
\begin{gathered}
\alpha \mathrm{Y}^{\wedge}+(1-\alpha) \mathrm{Y}^{\wedge}=\mathrm{A}_{1} \wedge+\alpha \mathrm{K}^{\wedge}+(1-\alpha) \mathrm{L}^{\wedge} \\
(1-\alpha)\left(\mathrm{Y}^{\wedge}-\mathrm{L}^{\wedge}\right)=\mathrm{A}^{\wedge}+\alpha\left(\mathrm{K}^{\wedge}-\mathrm{Y}^{\wedge}\right) \\
(1-\alpha) \mathrm{y}^{\wedge}=\mathrm{A}^{\wedge}+\alpha \mathrm{V}^{\wedge} \\
\mathrm{y}^{\wedge}=[1 /(1-\alpha)] \mathrm{A}^{\wedge}+[\alpha /(1-\alpha)] \mathrm{V}^{\wedge} \cdot{ }^{38}
\end{gathered}
$$

This result, a repeat of Eq. (4), underscores that as in the economy that moves from steady state to steady state with a fixed K-Y ratio, economic growth arises entirely from $\mathrm{A}_{1} \wedge$, i.e., Hickneutral technical change, and the technology multiplier. Decomposing $[1 /(1-\alpha)] \mathrm{A}_{1} \wedge$, the total

\footnotetext{
${ }^{38}$ Note that unlike the derivation in Section 2 and that for the conventional derivation of the neoclassical growth equation, the constraint of a fixed K-Y ratio is unnecessary; the simply emerges from the derivation without any priors, such as those associated with Kaldor's stylized facts of growth.
} 
contribution of $A_{1} \wedge$ consists of (i) $[(1-\alpha) /(1-\alpha)] A_{1} \wedge$, i.e., $A_{1} \wedge$, the direct impact effect of $A_{1} \wedge$ represented by an equi-proportional upward shift in the production function, and (ii) $[\alpha /(1-$ $\alpha)] \mathrm{A}_{1} \wedge$, the contribution from technical change resulting from the subsequent capital deepening, depicted by moving along the production function to its new steady state. This adjustment process is as shown in Fig. 2. Again, in the final equilibrium, $A_{2} \wedge=[1 /(1-\alpha)] A_{1} \wedge$, the Harrodneutral steady-state equilibrium, including the capital deepening, is a multiple of the initial Hicks-neutral invention technical change.

Another way to show this result is to convert Eq. (14) to another popular version of the growth accounting equation:

$$
\mathrm{y}^{\wedge}=\mathrm{A}_{1} \wedge+\alpha \mathrm{k}^{\wedge}
$$

where $\mathrm{k}^{\wedge}=\mathrm{K}^{\wedge}-\mathrm{L}^{\wedge}$. This version underscores the fact that, in accord with the definition of Hicks-neutral technical change, $A_{1} \wedge$ is measured at the point at which the K-L ratio is held fixed. Consequently whatever further growth arises due to capital deepening is represented by $\alpha\left(\mathrm{K}^{\wedge}\right.$ $\mathrm{L}^{\wedge}$ ). Substituting $\mathrm{k}^{\wedge}$ from Eq. (3), the representation of the capital-deepening component of the growth process, into Eq. (16) above and simplifying, we recover our representation $y^{\wedge}=[1 /(1$ $\alpha)] \mathrm{A}^{\wedge}+[\alpha /(1-\alpha)] \mathrm{V}^{\wedge}$.

Again, for the purpose of growth accounting, because $y^{\wedge}$ includes capital deepening, $A_{1}$ is not directly observable. As we observe proximate steady states in which capital deepening has substantially materialized, the observed technical change is $[1 /(1-\alpha)] \mathrm{A}_{1} \wedge$, i.e., the Harrod-neutral steady, $A_{2} \wedge$. Hence, our accounting equation is $y^{\wedge}=A_{2} \wedge+[\alpha /(1-\alpha)] V \wedge$, from which we can recover the initial Hicks technology impulse, $A_{1} \wedge=(1-\alpha) A_{2} \wedge$ and the conventional measure of total factor productivity (TFP).

With these two fundamental adjustments to growth analysis - incorporating the HicksHarrod paradigm and acknowledging the role that technical change plays in driving investment and capital deepening, the starting point for growth accounting is the Harrod version of the balanced growth equation as shown in Eq. (6) of Section 2:

$$
\mathrm{y}^{\wedge}=\mathrm{A}_{2}^{\wedge}+[\alpha /(1-\alpha)] \mathrm{V}^{\wedge}
$$

from which one can readily measure the relevant Harrod-neutral steady-state technical change: 


$$
\mathrm{A}_{2} \wedge=\mathrm{y}^{\wedge}-[\alpha /(1-\alpha)] \mathrm{V}^{\wedge}
$$

and, in turn, derive the initial rate of Hicks-neutral technical change and TFP:

$$
\mathrm{A}_{1} \wedge=\mathrm{TFP}=(1-\alpha) \mathrm{A}_{2} \wedge=(1-\alpha) \mathrm{y}^{\wedge}-\alpha \mathrm{V}^{\wedge}
$$

For the case in which $\mathrm{V}^{\wedge}=0$, Harrod-neutral technical change is simply $\mathrm{y}^{\wedge}$; for the case in which $\mathrm{V}^{\wedge}=0, \mathrm{y}^{\wedge}$ embodies changes associated with factors other than Harrod-neutral technical change, involving changes in the economy’s K-Y ratio. Hence, in order to strip away from $\mathrm{y}^{\wedge}$ sources of change other than those resulting from purely-labor augmenting technical change, the measure of $\mathrm{y}^{\wedge}$ must be adjusted by $[\alpha /(1-\alpha)] \mathrm{V}^{\wedge}$.

Additionally, consistent with the augmented version of the Solow model represented by Mankiw, Romer and Weil (1992), Eq. (17) can be expanded to include human capital, in which case, it would read:

$$
\mathrm{A}_{2} \wedge=\mathrm{y}^{\wedge}+[\alpha /(1-\alpha-\beta)] \mathrm{V}^{\wedge}-[\beta /(1-\alpha-\beta)] \mathrm{U}^{\wedge}
$$

where $\beta$ is human capital's output elasticity and $U^{\wedge}$ represents changes in conditions that determine the human capital-output $(\mathrm{H} / \mathrm{Y})$ ratio. Again, for $\mathrm{V}^{\wedge}=\mathrm{U}^{\wedge}=0$, the economy is operating in its steady state, so that the measured productivity growth is solely labor augmenting as represented by $y^{\wedge}$. For this case, the Hicks equivalence is measured as $(1-\alpha-\beta) A_{2}$.

At this point in the paper, possibly earlier, if one has accepted the basic argument of the paper, then as a fundamental cornerstone of the proposed growth-theoretic growth accounting approach, Eq. (18) may seem rather pedestrian. However, one implication of Eq. (18) is that it demonstrates how in his notable study of the sources of economic growth in the Four Asian Tigers, by attributing the full amount of investment in physical and human capital in these countries to sources other than on-going technical change, Alywn Young (1995) is likely to have seriously understated the contribution of technical change in the growth of these economies. Discounts in the contribution of technical change to the growth of living standards should result only from those increases in $\mathrm{K}$ and $\mathrm{H}$ in excess of the increase in $\mathrm{Y}$.

A further approach for reconciling the different representations of technical change and TFP change can be found in a certain underappreciated and underused corner of the growth 
accounting literature. Hsieh (1999) demonstrates the comparability of the primal and dual approaches to growth accounting. Starting with the national income identity $Y \equiv r K+w L$, he totally differentiates the expression with respect to time. The resulting rate of change version is:

$$
\begin{aligned}
& \mathrm{TFP}^{\wedge}=\mathrm{Y}^{\wedge}-\alpha \mathrm{K}^{\wedge}-(1-\alpha) \mathrm{L}^{\wedge}=\alpha \mathrm{r}^{\wedge}+(1-\alpha) \mathrm{w}^{\wedge} . \\
& \mathrm{TFP}^{\wedge}=\alpha(\mathrm{Y}-\mathrm{K})^{\wedge}+(1-\alpha)(\mathrm{Y}-\mathrm{L})^{\wedge}=\alpha \mathrm{r}^{\wedge}+(1-\alpha) \mathrm{w}^{\wedge} .
\end{aligned}
$$

Eqs. (19a) and (19b) demonstrate the equality of the primal and dual approaches to growth accounting in which the contributions of capital and labor are measured in terms of the changes in their respective marginal productivities and factor prices. ${ }^{39}$ Controlling for $\mathrm{r}^{\wedge}$ and $\mathrm{Y}^{\wedge}-\mathrm{K} \wedge$, both of these yield accurate measures of TFP and Hicks-neutral technical change. What they do not convey is that the total contribution to technical change, as represented by the Harrod-neutral measure is in fact $\mathrm{A}_{2} \wedge=[1 /(1-\alpha)]^{*} \mathrm{TFP}=\mathrm{y}^{\wedge}=\mathrm{w}^{\wedge}$, again controlling for $\mathrm{Y}^{\wedge}-\mathrm{K}^{\wedge}$ and $\mathrm{r}^{\wedge}$.

Growth accounting with deviations from the balanced growth path. Here we further extend our growth-theoretic approach to growth accounting. We start with a rate-of-change version of the steady-state capital accumulation equation. Substituting $V^{\wedge}=s^{\wedge}-(n+\delta)^{\wedge}$ into Eq. (17) gives:

$$
\mathrm{A}_{2} \wedge=\mathrm{y}^{\wedge}-[\alpha /(1-\alpha-\beta)] \mathrm{V}^{\wedge}+[\beta /(1-\alpha-\beta)] \mathrm{U}^{\wedge}
$$

The dual equivalent is:

$$
\mathrm{A}_{2} \wedge=\mathrm{w}^{\wedge}+[\alpha /(1-\alpha-\beta)] \mathrm{r}_{\mathrm{k}}^{\wedge}+[\beta /(1-\alpha-\beta)] \mathrm{r}_{\mathrm{h}} \wedge
$$

where $r_{k}$ and $r_{h}$ are the respective returns to physical and human capital.

In order to explore some of the complexity of this specification, we condense the specification to the standard total capital version, dropping $\mathrm{U} \wedge$ and $\mathrm{r}_{\mathrm{h}} \wedge$. We start with a rate-ofchange version of the steady-state capital accumulation equation. Substituting $V^{\wedge}=\mathrm{s}^{\wedge}-(\mathrm{n}+\delta)^{\wedge}$ into Eq. (17) gives:

\footnotetext{
${ }^{39}$ Note, however, that this formulation assumes that the respective factor income shares or output elasticities are constant. That is, because, the changes in the average products and those of the factor returns, $\mathrm{w}^{\wedge}$ and $\mathrm{r}^{\wedge}$, are equivalent only under the condition of fixed values for $\alpha$ and 1- $\alpha$.
} 
The difficulty with this dual relationship, is that it was derived under the assumption that $\alpha$ is fixed, so that $\alpha=r V$ and an increase in $\mathrm{Y} / \mathrm{K}$ (or Y/L) will result in an equi-proportional increase in $\mathrm{w}$ (or $\mathrm{r}$ ). Hence, $\mathrm{r}^{\wedge}=-\mathrm{V}^{\wedge}=\left[-\mathrm{s}^{\wedge}+(\mathrm{n}+\delta)^{\wedge}\right.$, i.e., a decline in the $\mathrm{K} / \mathrm{Y}$ ratio will be associated in an increase in the MPK and an increase in r, causing capital's factor income share will be unchanged. This has clearly not been the case for human capital in which the share of human capital in more developed economies has risen without a commensurate decline in the returns to human capital. ${ }^{40,41}$

Recognizing that $r=\alpha Y / K$, so that $\alpha^{\wedge}=r^{\wedge}+V^{\wedge}$, in Eq. (20a), we can substitute $\alpha^{\wedge}-r^{\wedge}$ for $\mathrm{V}^{\wedge}$ and in Eq. (20b), we can substitute $\alpha^{\wedge}-\mathrm{V}^{\wedge}$ for $\mathrm{r}^{\wedge}$. These various configurations provide a challenging, but potentially useful, means of identifying factors that are driving an economy off its steady state path, while also opening the door - as examined in the previous section - for investigating the role for $\mathrm{V}^{\wedge}$ and its determinants, i.e., $\mathrm{s}$ and $\mathrm{n}$-related factors, and $\mathrm{r}^{\wedge}$ spilling over to cause changes in $\alpha$, the technology multiplier. For example, Young (1995) shows that in Hong Kong and S. Korea, rising rates of savings and declining rates of population growth were associated with increases in the economies' capital income shares. While the capital income shares of Singapore and S. Korea fell marginally, these were also the two countries in which the share of the population enrolled in secondary school grew the most thereby likely contributing to large increases in in these economies in the human capital income shares, which Young does not separate from the total labor income shares. During 1960-1990, these four Asia economies clearly operated along a growth path that did not qualify as "balanced." However, it it likely that exogenous technical change and the expanding channels through which it was absorbed into the economy nonetheless played the lead role in driving these economies to high-income status.

By comparison Evans (2000) finds that over the 50-year period, 1947-98, the U.S. economy arguably closely tracked a balanced growth path. He finds that the depreciation rate of the U.S. economy systematically rose, as did the share of investment in equipment compared with structures. Over the same period, the gross investment rate in the U.S. also rose. According to Evans, the rise in the U.S. gross investment rate combined with a rise in the depreciation rate served to explain the mean-stability of the net investment rate. This is turn is consistent with the finding of a mean-stationary rate of return on capital, i.e., $\mathrm{r}^{\wedge}=0$ during the latter half of the $20^{\text {th }}$

\footnotetext{
${ }^{40}$ A salient reason is likely to be that offered by Easterly (2002), in his chapter "Tales of Increasing returns: leaks, matches, and traps."

${ }^{41}$ A subsequent version of this paper will examine the total derivative in which $\alpha=r s /(n+\delta)$, i.e., Eq. (14)
} 
century. Hence, based on Evan's findings, the rate of productivity growth for the U.S. economy over the period 1947-98, which is also the rate of growth of Harrod-neutral technical change, is $2 \%$. Given that $\alpha=1 / 3$, the counterpart rate of Hicks-neutral technical change was $1.33 \%$. Including human capital's output elasticity of $1 / 3$, such that the total elasticity expands to $2 / 3$, the $2 \%$ rate of Harrod neutral technical change implies an equivalent Hick-neutral rate of just $0.67 \%$. Based on Evan's findings, the bottom line appears to be that changes in s and $\delta$ have had offsetting effects, so that so long as changes in the rate of population growth have been of a second-order magnitude (e.g. < 1\%), capital's output elasticity remained approximately fixed during the latter half of the $20^{\text {th }}$ century. More recent experience suggests that during the first part of the $21^{\text {st }}$ century, the factor income shares may exhibit some change. For many countries, these parameters exhibit far less stability than they have for the U.S.

For the growth accountant, a key challenge is not only to narrow the analysis to the contribution of technical change, although arguably that should be the principal motive for the growth accounting exercise. In order to achieve this, growth accountants need also to identify other factors, in particular structural changes and policy changes that are affecting the path of long-run growth. Within our framework above, these factors most naturally fit in with the context of factors that are contributing to significant changes in $\mathrm{V}$ and $\mathrm{U}$, the economy's physical and human capital intensities. A central conclusion to the analysis in this section is that for the purpose of growth accounting, over any given period, the growth accountant should first compute the change in $\mathrm{y}^{\wedge}$ and $\mathrm{w}^{\wedge}$. As shown in Eqs. (20a) and (20b), differences in these changes may arise from differences between $\mathrm{U}^{\wedge}$ and $\mathrm{r}_{\mathrm{k}} \wedge$ and/or $\mathrm{V} \wedge$ and $\mathrm{r}_{\mathrm{h}} \wedge$. From the perspective of this growth-theoretic approach to growth accounting, a key determination is whether, say for the primal condition, $\mathrm{V}^{\wedge}=\mathrm{U}^{\wedge}=0$. If not, fertile ground opens for the growth accounting exercise in which rates of savings and investment in physical and human capital and changes in demographic structure appear as key candidates for understanding the factors that have force the economy off its balanced growth path. Furthermore, to the extent that the relevant capital elasticities $-\alpha$ and $\beta$ - have changed, powerful conditions may have entered the economy, conceivably associated with changes in patterns of investment and demographic structure, that are substantially altering the capacity of the economy to absorb and magnify the impacts of Hicks-neutral technical change. 


\section{Final Remarks}

Most of the insights in this paper arise from the recognition that representations of technical change in the standard growth literature are fundamentally misconstrued. Rather than competing for their places in neoclassical growth theory and growth accounting, Hicks invention-neutral technical change and Harrod steady-state technical change represent inseparable bookends that define the growth process. In the final steady state, Harrod change owes its existence to Hicks invention change and the induced accumulation of millions of investments and refinements that at last culminate in sustained improvements in everyday life. It is critical that our growth models recognize and incorporate the evolution of these stages in this process of technological development.

The most important outcomes of this paper entail recognition that: (i) economic growth is a process, not a steady state. While the stylized facts characterizing the steady state provide a critical frame for growth analysis, they should not obscure our understanding of the intrinsic nature of the development and diffusion of technology; (ii) the sequential nature of technical change distinguishes between elements of technical change that assume the characteristics of a public good contrasted with the characteristics of individual economies that differentiate their abilities to absorb and propagate exogenous technical change; (iii) by differentiating the sequencing of technical change, the neoclassical model, as reformulated, has within its specification the elements needed not only to model and describe steady state growth but also to explain the circumstances that can occasion the dramatic departures from steady state growth that may be the most critical determinants of differences in living standards across nations; (iv) such elements include both the levels, as well as changes, in rates of savings and demographic structure affecting the accumulation of physical and human capital, and (v) with neoclassical growth framed by Hicks invention neutrality and growth accounting framed by the Harrod steady state, it becomes possible for these two heretofore disparate fields of growth analysis to function in a mutually consistent, collaborative manner.

The past half century has generated a huge and rich swath of growth theory and growth accounting literature. This paper attempts to bring together and highlight a range of inconsistencies and possibilities that have emerged from this literature. Most importantly, the paper hopefully demonstrates that given the differences in the magnitudes and change in their technology multipliers, all countries have different capacities to absorb, process, and learn from a 
somewhat uniform global technology opportunity sets. Given the wide range of on-going innovations and permutations in the literature, it is certain that many of the principles and perspectives set forth in the paper warrant conditioning, clarification, or outright correction. This paper has hopefully set the stage for such an effort. 


\section{References}

Acemoglu, Daron, (2009). Modern Economic Growth, Princeton University.

Aghion and Howitt (1992), “A Model of Growth Through Creative Destruction,” Econometrica, Vol. 60, No. 2 (March, 1992), 323-351.

Arrow, Kenneth J. (1962) "The Economic Implications of Learning by Doing." Review of Economic Studies 29: 155-73.

Barro, Robert J. (1990), “Government Spending in a Simple Model of Endogenous Growth,” Journal of Political Economy, 98:S103-25.

Barro, R.J. and X. Sala-i-Martin, (1995). Economic Growth, New York, McGraw-Hill.

Besomi, Daniele, 1999. "Harrod on the classification of technological progress. The origin of a wild-good chase,” BNL Quarterly Review, no. 208, March 1999.

Denison, Edward (1974) Accounting for United States economic growth, 19291969 (Washington D. C., 1974).

Diamond, Peter, McFadden, Daniel, Rodriguez, Miguel (1978), “Measurement of the Elasticity of Substitution and the Bias of Techical Change,”, in M. Fuss and D. McFadden, Production Economics: A Dual Approach in Theory and Applications, Ch. 4, Vol. 2, Amsterdam: North Holland,.

Diwan, Romesh, K, "Bias in the Measure of Technical Change," http://www.jstor.org/stationary/2329586?seq=1\#page_scan_tab_contents

Easterly, William (2002), The Elusive Quest for Growth, MIT Press, Cambridge, MA.

Eichengreen, Barry, Donghyun Park, and Kwanho Shin (2011), "When Fast Growing Economies Slow Down: International Evidence and Implications for China,” NBER Working Paper 16919 http://www.nber.org/papers/w16919.

Evans, Paul, 1998. "Using Panel Data to Evaluate Growth Theories," International Economic Review, vol. 39(2), pages 295-306, May.

Evans, Paul, 2000. “US Stylized Facts and Their Implications for Growth Theory,” March 2000.

Gao Jian and Jefferson, Gary H. (2007), “Science and Technology Takeoff in China: Sources of R\&G Intensification,” Asia Pacific and Business Review, 13:3, 357-371.

Gerschenkron, Alexander (1962), Economic backwardness in historical perspective, a book of essays, Cambridge, Massachusetts: Belknap Press of Harvard University Press. 
Grossman, Geme M., Helpman, Oberfield Ezra, and Samson Thomas, (2016). "Balanced Growth Despite Uzawa,” NBER Working Paper, 21861, January 2016.

Harrod, Roy F. 1961b_, “The 'neutrality’ of improvements,” Economic Journal, vol. LXXI, June, pp. 300-304.

Hicks, John Richard (1963) The Theory of Wages, Macmillan, London, $2^{\text {nd }}$ edition.

Hsieh, Chang-Tai (1999), "Productivity Growth and Factor Prices in East Asia

The American Economic Review, Vol. 89, No. 2, Papers and Proceedings of the One Hundred Eleventh Annual Meeting of the American Economic Association. (May, 1999), pp. 133-138.

Hulton, Charles R. (1992), "Growth Accounting When Technical Change is Embodied in Capital,” American Economic Review, Vol. 82, No. 4 (Sep., 1992), pp. 964-980.

Hulton. Charles R. (2009). “Growth Accounting,” Working Paper 15341

http://www.nber.org/papers/w15341, (September, 2009)

Jaffe, Adam B. \& Josh Lerner (2007). Innovation and Its Discontents:

How Our Broken Patent System is Endangering Innovation and Progress, and What to Do About It, Princeton University Press.

Jones, Charles I. and Dean Scrimgeour, “The Steady-State Growth Theorem:

Understanding Uzawa (1961)”, August 16, 2005, https://www.aeaweb.org/assa/2006/0106_1430_0702.pdf

Jones, Charles I. and Romer, Paul M. (2010), “The New Kaldor Facts: Ideas, Institutions, Population, and Human Capital,” American Economic Journal: Macroeconomics 2(1), 224-45.

Jones, Charles (1995), “R\&D-Based Models of Economic Growth,” The Journal of Political Economy, 103, 4: 759-784.

Jones, Charles and Dietrich Vollrath (2013), Introduction to Economic Growth, W.W. Norton \& Co., New York and London.

Jones, Hywel (1975), Modern Theories of Economic Growth, Thomas Nelson and Sons, Ltd.

Jorgenson, Dale, “Innovation and Productivity Growth,” American Journal of Agricultural Economics, 93(2): 276-296;

Kaldor, Nicholas (1957). "A Model of Economic Growth". The Economic Journal 67 (268): 591-624

Kaldor, N. (1961), "Capital Accumulation and Economic Growth,” in F. A. Lutz and D. C. Hague, editors, The Theory of Capital. New York: St. Martin's Press. 
Lucas (1988), “Human Capital and Endogenous Growth,” Journal of Monetary Economics 22 (1988) 3-42. North-Holland

Mankiw, Romer, Weil (1992), “A Contribution to the Empirics of Economic Growth,” Quarterly Journal of Economics.

Nelson, Richard R. and Phelps, Edmund S. (1966) "Investment in Humans, Technological Diffusion, and Economic Growth. “American Economic Review, Vol. 56, No. 1/2. (Mar., 1966), pp. 69-75.

Richard R. Nelson and Sidney G. Winter, "Neoclassical versus evolutionary theories of economic growth: critique and prospects,” The Economic Journal, Vol. 84, No. 336 (Dec., 1974), pp. 886-905.

Prescott, Edward C., (1998). “Needed: A Theory of Total Factor Productivity,” Lawrence R. Klein Lecture, International Economic Review, Vol. 39, No. 3 (Aug., 1998), pp. 525-551.

Rebelo, Sergio T. (1991): “Long-Run Policy Analysis and Long-Run Growth,” Journal of Political Economy, 99(3), 500-521.

Romer, P.M. (1986), “Increasing Returns and Long-Run Growth,” Journal of Political Economy 94: 1002-1037.

Romer, Paul M. (1990) “Endogenous Technological Change.” Journal of Political Economy 98 (5): S71-S102.

Romer, Paul M. (1994a) “New Goods, Old Theory, and the Welfare Costs of Trade Restrictions.” Journal of Development Economics 43: 5 - 38.

Romer (1994b), “Origins of Endogenous Growth,” Journal of Economic Perspectives, 8,1:3-22

Rostow, Walter,1960, The Stages of Economic Growth: A Non-Communist Manifesto, Cambridge, MA: Cambridge University Press.

Schultz, Theordore, W. (1975) “The Value of the Ability to Deal with Disequilibria.” J. Economic. Literature. 13, no. 3 (September 1975): 827-46.

Solow, Robert M., 1956. “A Contribution to the Theory of Economic Growth.” Quarterly Journalof Economics 70 (1): 65 - 94.

Solow, Robert M. 1957. “Technical Change and the Aggregate Production Function,” Review of Economics and Statistics, pp. 312-20.

Solow, Robert M. (1960). “Investment and Technical Progress,” in Arrow, K, Karlin, S, and Suppes, P. (eds) Mathematical Methods in the Social Sciences, Stanford University Press. 
Solow, Robert M., (1988). “Growth Theory and After,”The American Economic Review Vol. 78, No. 3 (Jun., 1988), pp. 307-317.

Solow, Robert M. (2000), Growth Theory: An Exposition, Oxford University Press.

Uzawa, Hirofumi (1961) "Neutral Inventions and the Stability of Economic Growth,” Review of Economic Studies, 28: 117-124.

Young, Alywn (1995) "Confronting the Statistical Realities of the East Asian Growth Experience,” Quarterly Journal of Economics, 110(3):641-68. 


\begin{tabular}{|c|c|c|}
\hline Paper & $\begin{array}{l}\text { Production function: } \\
\text { representation of } \\
\text { technical change }\end{array}$ & Comments \\
\hline $\begin{array}{l}\text { Aghion and } \\
\text { Howitt (1992) }\end{array}$ & $\begin{array}{l}\text { Hicks-like; innovation } \\
\text { centers on intermediate } \\
\text { goods. }\end{array}$ & No physical or human capital. \\
\hline Romer (1990) & Harrod & $\begin{array}{l}\text { Relies on scale effects of population in the generation of } \\
\text { R\&D, i.e., a } 1 \% \text { increase in S\&T personnel leads to a } \\
1 \% \text { increase in the growth of A (i.e., g). }\end{array}$ \\
\hline Jones (JPE, 1995) & Harrod & $\begin{array}{l}\text { Jones shows that empirical analysis refutes the scale } \\
\text { assumption of Romer and others. But in modeling } \\
\text { around this assumption, Jones encounters dilemmas: In } \\
\text { order to eliminate scale effects, he finds that traditional } \\
\text { policies, assumed by Solow, Romer, and others to be } \\
\text { exogenous, in fact affect the path of long-run growth. }\end{array}$ \\
\hline $\begin{array}{l}\text { Romer (JPE, } \\
\text { 1986) }\end{array}$ & $\begin{array}{l}\text { Harrod with A(t) re- } \\
\text { presenting labor-aug- } \\
\text { menting technology of } \\
\text { the aggregate economy. } \\
\text { Implicitly Hicks? }\end{array}$ & $\begin{array}{l}\text { Question: how does technology become embodied in } \\
\text { capital, so that new vintages of capital will accumulate } \\
\text { in K(t), which becomes the source of purely labor- } \\
\text { augmenting technical change in subsequent periods? }\end{array}$ \\
\hline $\begin{array}{l}\text { Lucas (JME, } \\
\text { 1988) }\end{array}$ & $\begin{array}{l}\text { Technology-biased in } \\
\text { factors other than labor } \\
\text { and, in particular, } \\
\text { unskilled labor. }\end{array}$ & $\begin{array}{l}\text { This paper considers the prospects for constructing a } \\
\text { neoclassical theory of growth and international trade } \\
\text { that is consistent with some of the main features of } \\
\text { economic development. Three models are considered } \\
\text { and compared to evidence: a model emphasizing } \\
\text { physical capital accumulation and technological change, } \\
\text { a model emphasizing human capital accumulation } \\
\text { through schooling and a model emphasizing specialized } \\
\text { human capital accumulation through learning-by-doing. }\end{array}$ \\
\hline Rebelo (1991) & $\mathrm{Y}=\mathrm{AK}$ assumes Hicks & $\begin{array}{l}\text { Includes both physical and human capital, but omits } \\
\text { unskilled labor altogether. In doing so, this model } \\
\text { effectively adopts the assumption of Hicks-neutral } \\
\text { technical change in which all of the included factors } \\
\text { grow at a constant rate, g. }\end{array}$ \\
\hline
\end{tabular}


Figure 1. The impact of technical change $\left(A_{0} \rightarrow A_{1}\right)$ : Hicks vs. Harrod.

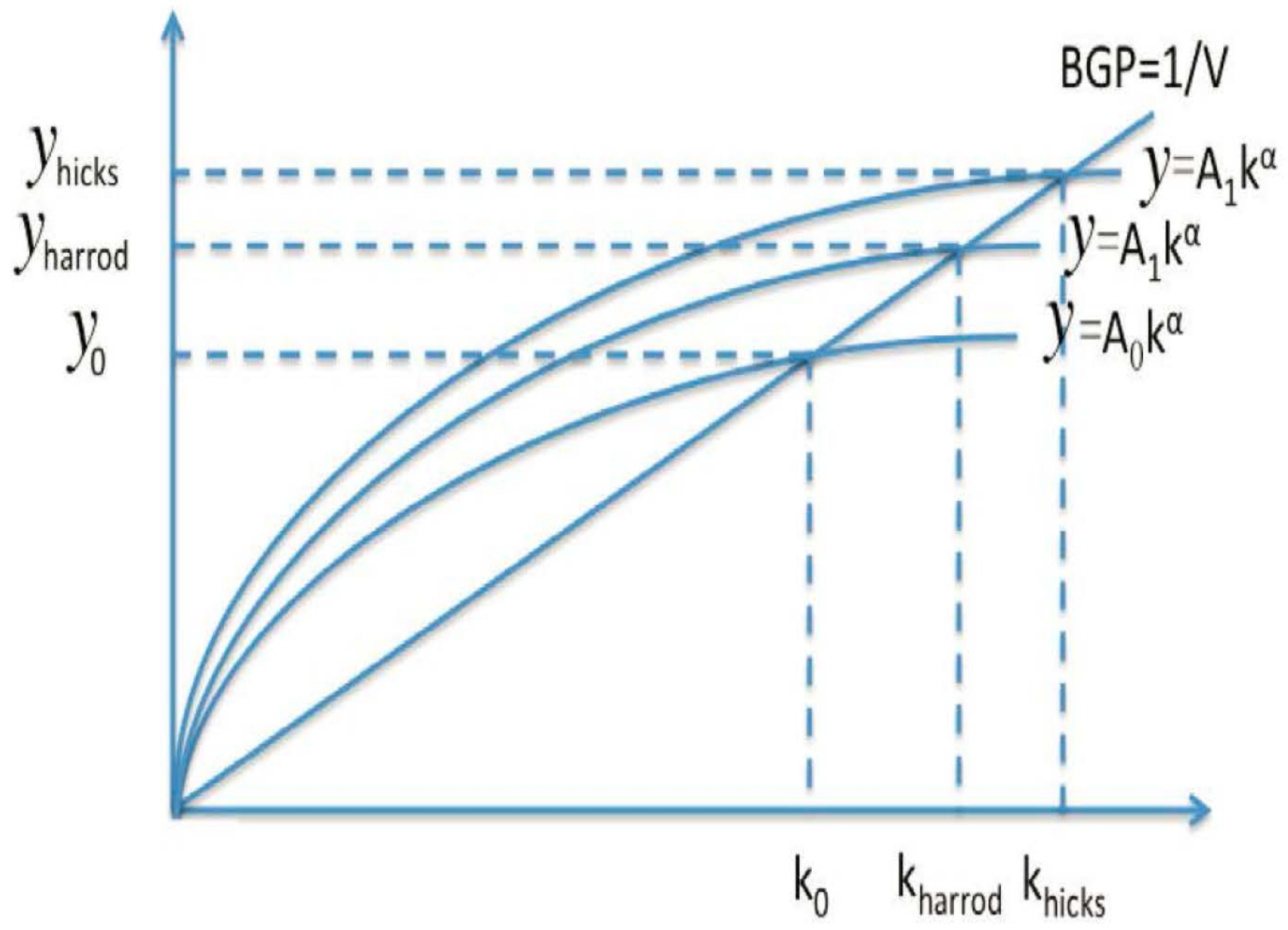


Figure 2

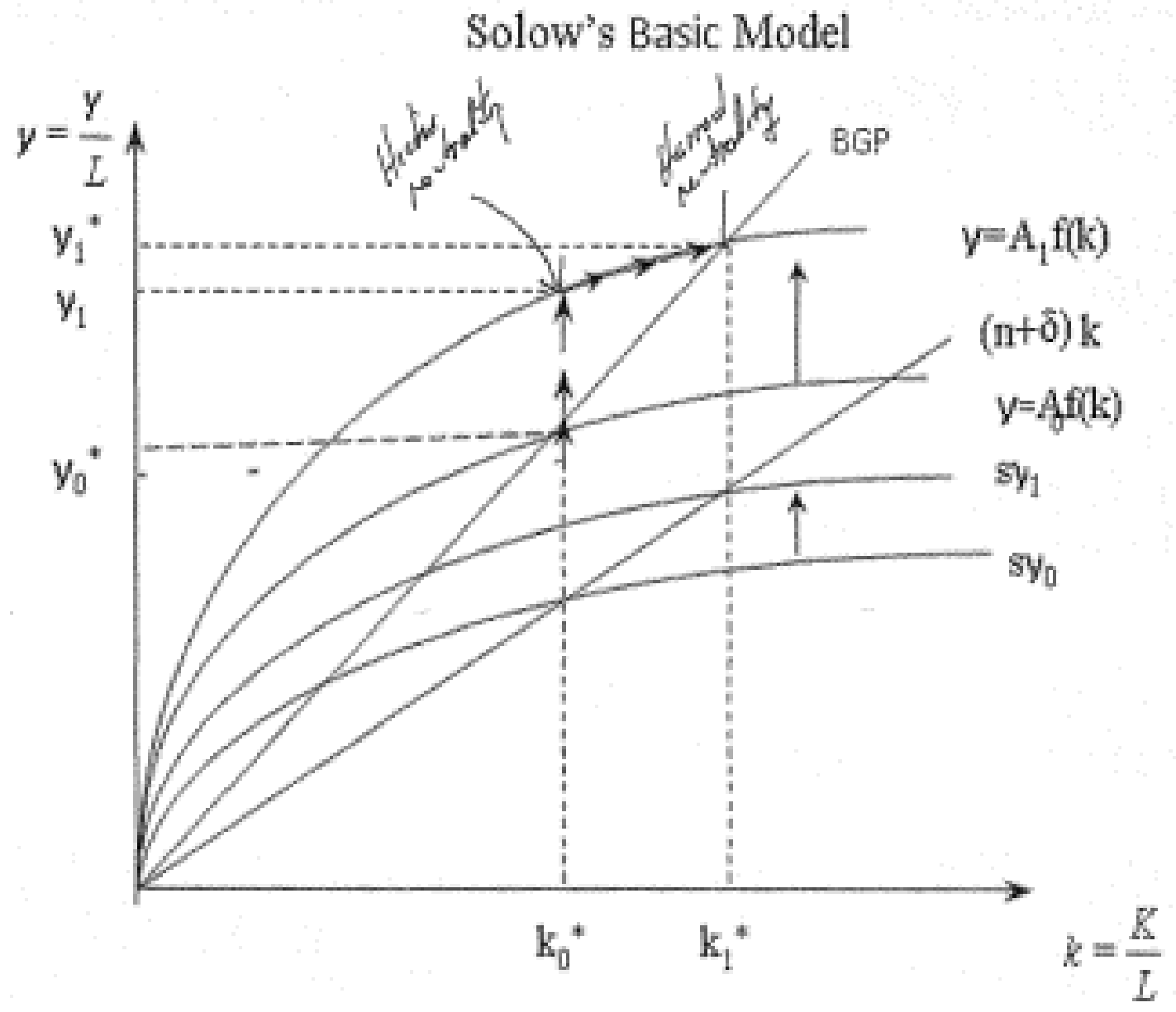


Figure 3. The Technology Multiplier

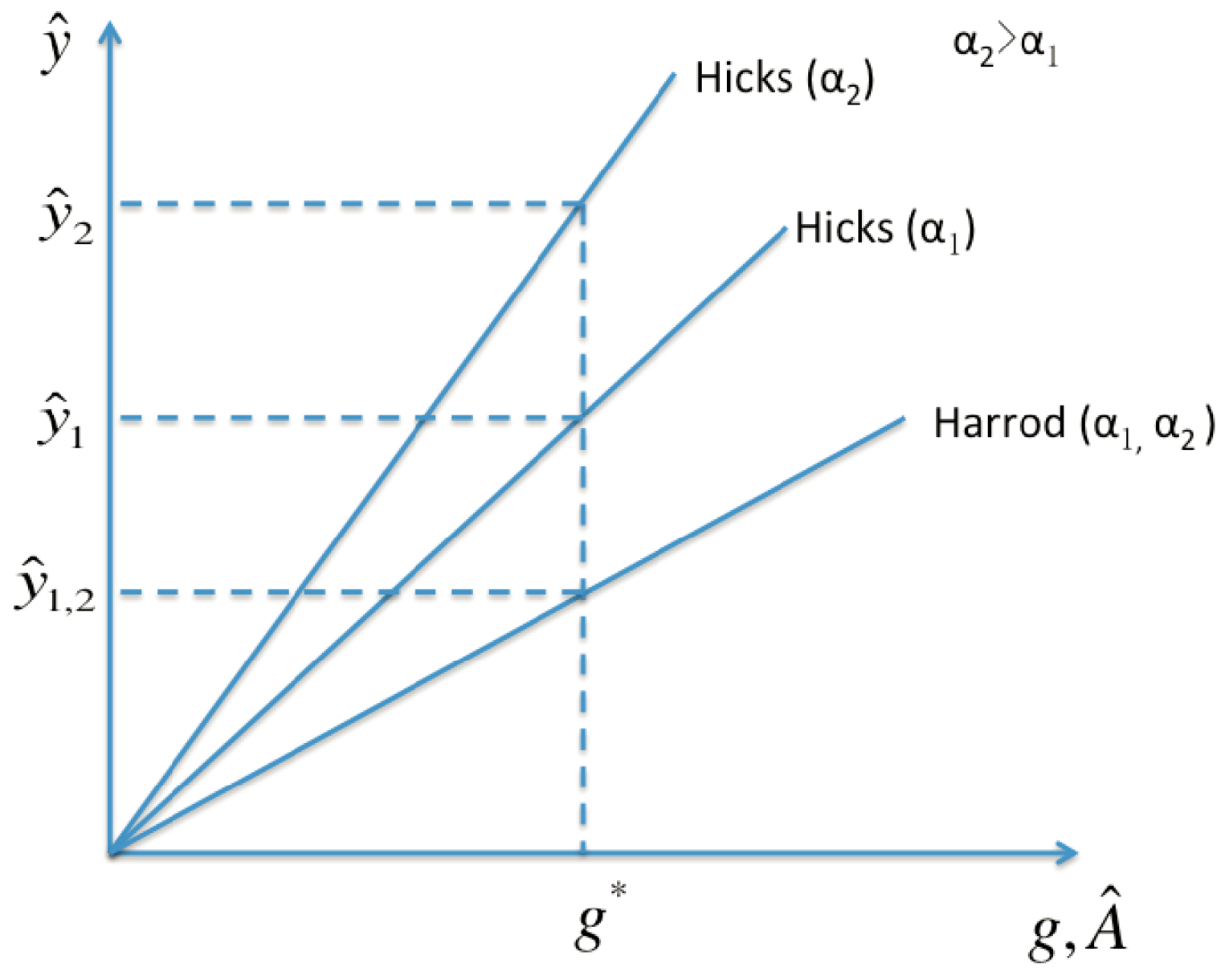


Annex A . A Representation of the Conventional Neoclassical Growth Model

Figure A-1: The conventional representation of the neoclassical model in the steady state with technical change. $\left(\mathrm{y}^{\sim}=\mathrm{Y} / \mathrm{AL} ; \mathrm{k}^{\sim}=\mathrm{K} / \mathrm{AL}\right)$

Figure A-2: An extrapolation of the production function with the curvature (properties) consistent with the savings schedule shown in Figure A-1. Figure A-2 demonstrates how an increase in technical change, (i.e., A'> A) creates disequilibrium, when then gropes its way back to the original steady state.

Figure A-1: The steady state with Harrod-neutral technical change

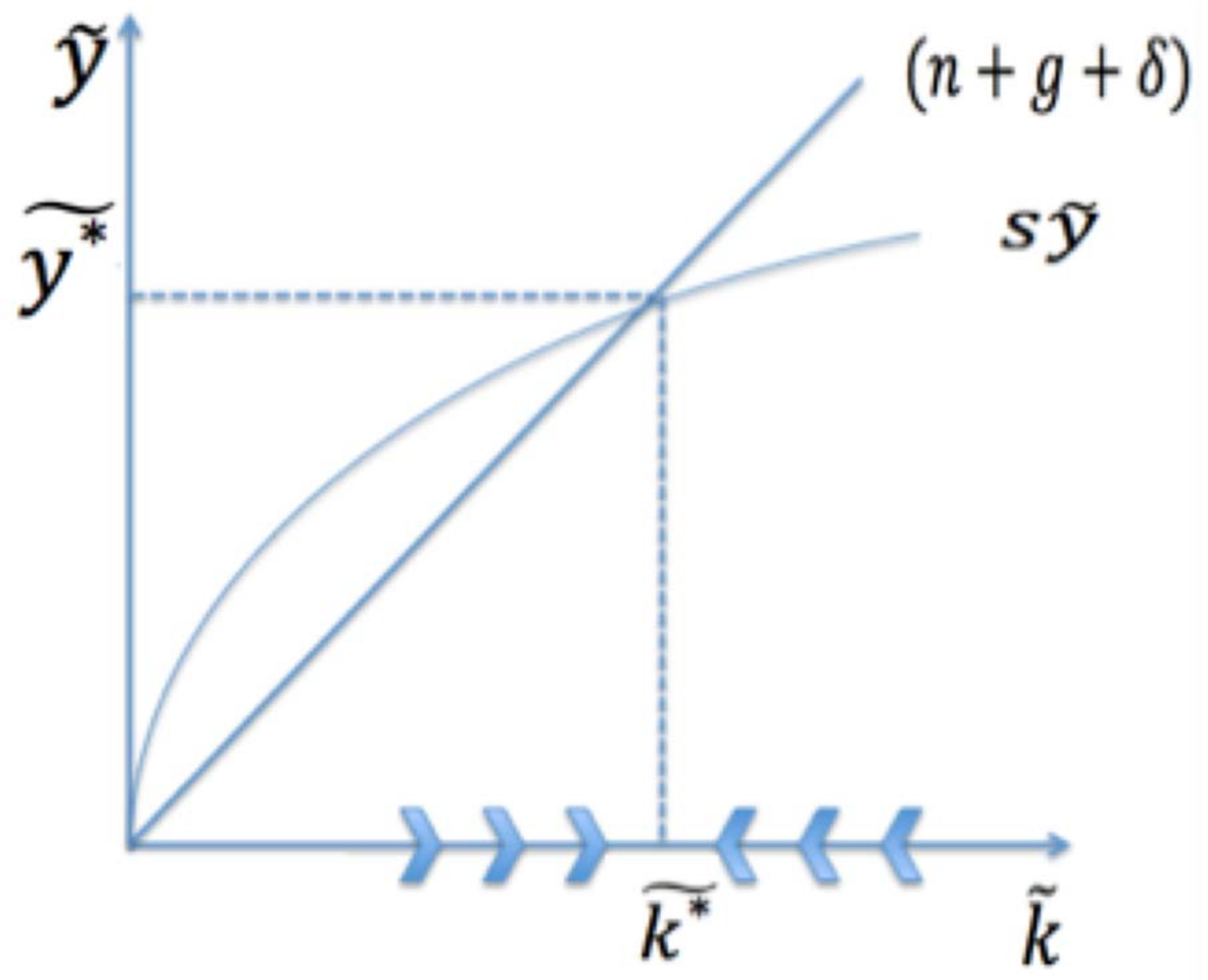


Figure A-2

Labor-augmenting Technical Change (A $\uparrow)$ : a Dynamic View

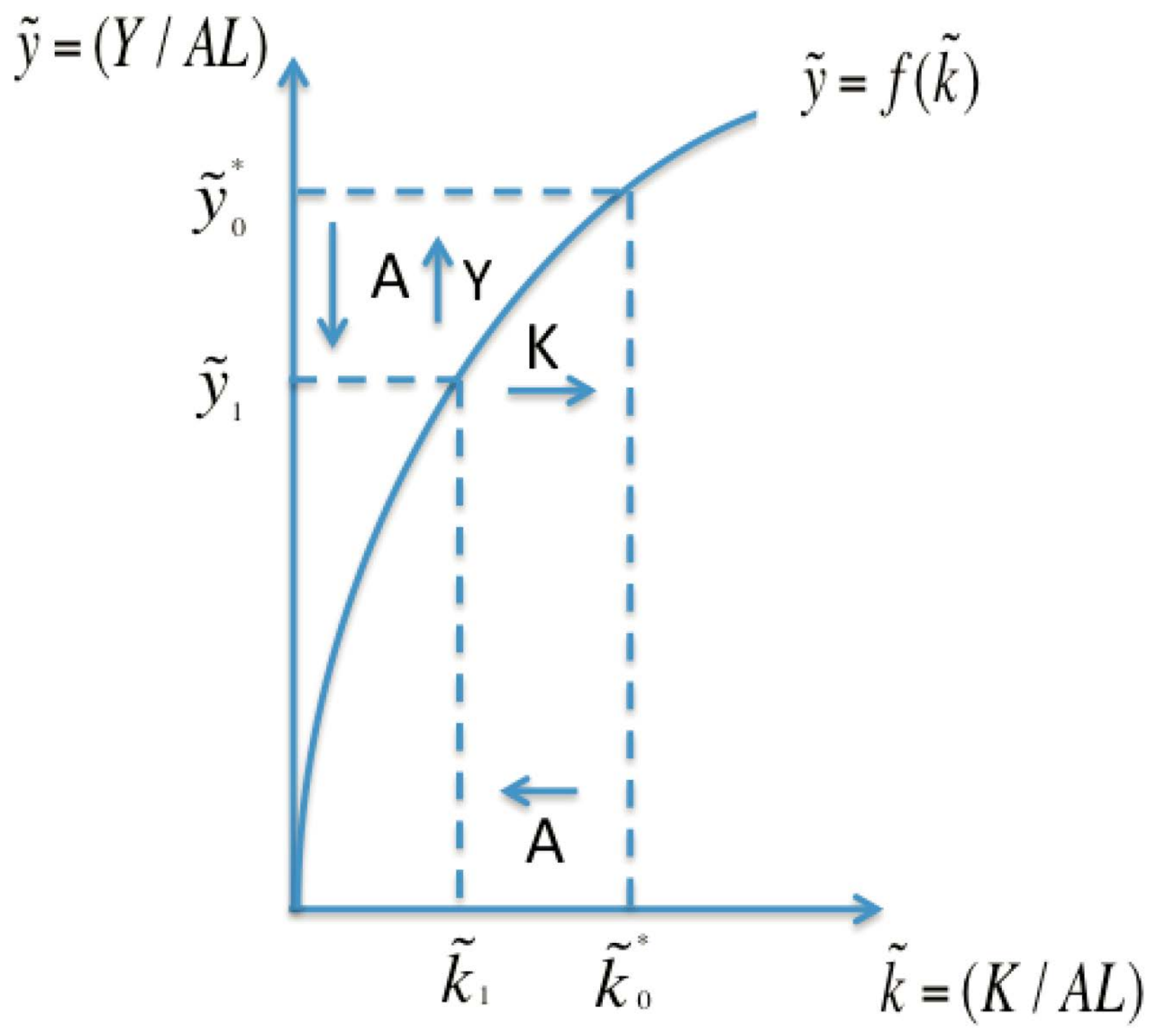


Annex B. Micro-foundations of growth theory: Harrod-neutral steady-state (only) technical change

Figure B- 1 begins with a standard production isoquant $A_{0} A_{0}$ in K-L space, in which $A_{0} A_{0}$ represents a locus of $(K, L)$ combinations that are able to produce a fixed level of output $\mathrm{Y}^{*}$. The curvature of the isoquant is intended to represent a unitary substitution elasticity. We start at the equilibrium, $\mathrm{A}$, along a given $\mathrm{K} / \mathrm{L}$ ratio. Beginning at $\mathrm{A}$, we demonstrate two types of technical innovation. The first is Hicks-neutral, a uniform shift of the isoquant toward the origin to $\mathrm{A}_{\mathrm{H}} \mathrm{A}_{\mathrm{H}}$. At $\mathrm{B}$, the firm is able to produce the same amount as it had at $\mathrm{A}$, using the old technology.

The contrasting technical change is labor-biased. This change is represented by an inward shift of the original $\mathrm{A}_{0} \mathrm{~A}_{0}$ isoquant to $\mathrm{H}$, representing the identical degree of labor-saving technical change as that achieved by the Hicks-neutral shift, $\mathrm{A}_{\mathrm{H}} \mathrm{A}_{\mathrm{H}}$. For the labor-biased change, because only labor enjoyed the savings increment, while capital did not, along $A_{L} A_{L}$ output is less than that for its Hicks counterpart, i.e., less than $\mathrm{Y}^{*}$.

In order for $\Delta A_{L}$ to be sufficient to achieve the same $Y^{*}$ as $\Delta A_{H}$, the following condition must hold: $Y^{*}=K^{\alpha}\left(A_{L} L\right)^{1-\alpha}=\left(A_{H} K\right)^{\alpha}\left(A_{H} L\right)^{1-\alpha}$. Differentiating $Y^{*}$ w.r.t. $A_{L}$ and $A_{H}$, setting $d Y^{*} / Y^{*}$ $=0$, and solving yields $d A_{L} / A_{L}=[1 /(1-\alpha)] \mathrm{dA}_{H} / A_{H}$. This result implies that for say $\alpha=2 / 3$, in order to maintain the same $\mathrm{Y}^{*}$, the labor-augmenting technical change must be $50 \%$ greater than the counterpart Hicks-neutral change.

Thus, in order to produce the same original output, $A_{L} A_{L}$ must further shift to $A_{L}{ }^{\prime} A_{L}$ '. At $B$, where labor is more productive along $A_{L}$ ' $A_{L}$ ' than it is along $A_{H} A_{H}$, and capital is more productive along $\mathrm{A}_{\mathrm{H}} \mathrm{A}_{\mathrm{H}}$, each of the new technologies produces the same original level of output (and an equally higher level of output per capita) than it had at A.

The isoquant $A_{L}$ ' $A_{L}$ ' is a generic description of labor-biased technical change - a locus of points along which each $(\mathrm{K}, \mathrm{L})$ combination produces $\mathrm{Y}^{*}$. By contrast, for Harrod-neutral technical change, there is but one production combination that is consistent with Harrod's stylized facts such that K/Y and $r$ are unchanged, while labor's marginal product has risen. In Fig. B-1, that is the point at $\mathrm{L}$, which is consistent with a constant $\mathrm{K}-\mathrm{Y}$ ratio (i.e., $\mathrm{K}_{0} / \mathrm{Y}^{*}$ ) and, given fixed factor shares, also a constant $\alpha$ and MPK, consistent with the unchanged rental cost of capital, $\mathrm{r}^{42}$ The equilibrium at $\mathrm{L}$, in turn, determines the factor price line, $\mathrm{p}_{\mathrm{L}} \mathrm{p}_{\mathrm{L}}$ (i.e., $\mathrm{dK} / \mathrm{dL}=-\mathrm{w}_{\mathrm{L}} / \mathrm{r}$ ), which is less steep than that for the Hicks equilibrium at $\mathrm{H}$, as shown by $\mathrm{p}_{\mathrm{H}} \mathrm{p}_{\mathrm{H}}$ (i.e., $\mathrm{dK} / \mathrm{dL}=-\mathrm{w}_{\mathrm{H}} / \mathrm{r}$ ). At $\mathrm{H}$ and $\mathrm{L}$, representing the labor-saving increases resulting from the Hicks-neutral and the labor-

\footnotetext{
${ }^{42}$ Note that the dynamic adjustment process for the labor-augmenting case and equilibrium at $\mathrm{L}$ are consistent with the adjustment process shown in Fig. A-2; the equilibrium at $\mathrm{H}$ is consistent with the adjustment process shown in Figure 2.
} 
biased technical change respectively, labor's marginal product and wage have risen more from the Hicks innovation than the purely labor-biased innovation. This is because with the Hicksneutral change, the increase in capital's marginal product results in more capital-deepening than that resulting from the labor-only augmenting effect of $\mathrm{dA}_{\mathrm{L}}$.

From the perspective of growth theory and Kaldor's stylized facts, the conditions at $\mathrm{H}$ (Hicks) and L (Harrod) are observationally equivalent. The K-Y ratios are identical; the MPK has been driven back to its original level consistent with the historical rate of return to capital, $r$. The MPL has risen. However, at $L$, as a measure of technical change, its description fits only one classification: it appears to be purely Harrod-neutral, labor-augmenting technical change. In fact, as shown in Figure B-1, that condition is but a unique equilibrium condition resulting from the more general labor-biased technical change. ${ }^{43}$ Furthermore, it, in turn, represents an alternative to a far more plausible scenario shown at $\mathrm{H}$, which is the Hicks invention-neutral scenario in which capital, too, has been the direct beneficiary of technical change.

The key insight of this analysis is that Harrod-neutral technical change and generic laboraugmenting (saving) technical change are not one-and-the-same. In the steady-state, Harrodneutral technical change exists only along the ray $\mathrm{K}_{0}$ LHA. It cannot be represented by an isoquant. Moreover, along this ray where the K-Y ratio is fixed, all of the points for which the $\mathrm{K}-\mathrm{Y}$ ratio is fixed are observationally equivalent for a variety of different factor-augmenting possibilities, so long as the underlying substitution elasticity is unity.

In conclusion, Harrod-technical change exists only in an equilibrium steady state. It is the final outcome of a growth process; not an initiating factor as are Hicks-neutral and labor-augmenting technical change as represented by a shift in an isoquant which is the established method of representing technical change.

\footnotetext{
${ }^{43}$ For example, in Acemoglu (2009, p. 59), the isoquant labeled as Harrod-neutral should receive the more general labor of "labor-augmented."
} 
Figure B-1: Hicks-Harrod Observational Equivalence:

Creating Harrod-neutral Steady State Technical change

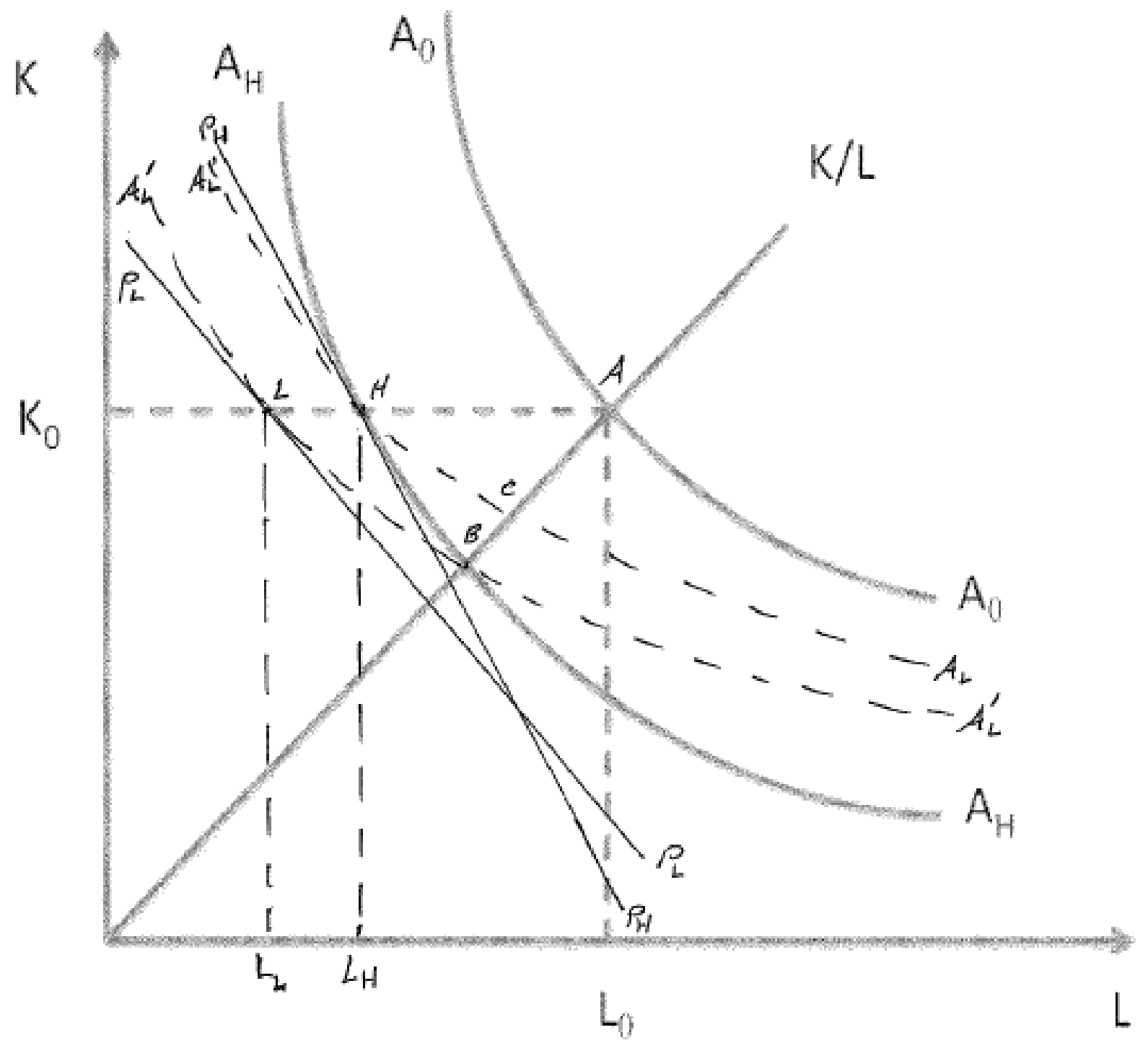


Annex C. An Increase in the Rate of Technical Change: A Purgatory Paradox

What impact does an increase in g have on the growth of output per capita, i.e., $\mathrm{y}^{\wedge}$ ?

First, we reproduce Eq. (6): $\mathrm{y}^{\wedge}=\mathrm{g}+[\alpha /(1-\alpha)] \mathrm{V}^{\wedge}$, where $\mathrm{g}$ is the rate of growth of Harrod-neutral technical change.

Let's assume that $\alpha=1 / 3, \mathrm{~s}=30 \%, \mathrm{n}=2 \%, \delta=10 \%$. Initially, $\mathrm{g}=2 \%$. Therefore, in the steady state, $V=K / Y=s /(n+g+\delta)=30 / 14=2.143$. Since $V^{\wedge}=0$, the rate of steady state growth $=2 \%$.

Now raise the growth of $g$ by $1 \%$, from $2 \%$ to $3 \%$. As shown in the steady-state condition, the impact on the K-Y ratio of an increase in $\mathrm{g}$ is identical to an equi-proportional increase in $\mathrm{n}$ or $\delta$. According to the steady-state condition, K/Y must decline. This can be seen in Fig. A-1, in which a reduction in $\mathrm{s} /(\mathrm{n}+\mathrm{g}+\delta)$ causes the required investment curve to shift back along the available savings curve, occasioning an increase in $\mathrm{y}^{\sim *} / \mathrm{k} \sim *$ (i.e., a decline in $\mathrm{K} / \mathrm{Y}$ ). In the new steady state, with a $1 \%$ increase in $\mathrm{g}$ (or $\mathrm{n}$ or $\delta$ ), the new steady state $\mathrm{K}-\mathrm{Y}$ ratio will be $\mathrm{V}=2$. The percentage decline in $\mathrm{V}$ is $7.15 \%$.

Hence, as a result of the change in g, during the transition to the new steady state, the rate of growth, $\mathrm{y}^{\wedge}=3 \%-(0.5) * 7.15 \%=-0.08 \%$. This implies a precipitous decline in $\mathrm{y}^{\wedge}$ from the original steady state balanced growth path as the economy labors to get to its new steady-state equilibrium of $3 \%$ !

Moreover, as $\alpha$ increases, the decline resulting from the $1 \%$ increase in $\mathrm{g}$ becomes all the more precipitous, e.g. for the Mankiw-Romer-Weil case (1995) in which $\alpha=2 / 3$. For this value of $\alpha$, as a result of the $1 \%$ increase in $\mathrm{g}$, the $7.15 \%$ decline in the $\mathrm{K}-\mathrm{Y}$ ratio translates into a $14.3 \%$ decline in the growth of output per capita.

Why is $\mathrm{y}^{\wedge}$ so perversely sensitive to increases in g? Why should increases in $g$ that in the standard theory serve to reduce the K-Y ratio send the economy into a tailspin? Take a Harrodversion of a Cobb-Douglas production function with CRS and capital's share $=\alpha$. Now take the rate of change version:

$$
\mathrm{Y}^{\wedge}=(1-\alpha) \mathrm{A}^{\wedge}+(1-\alpha) \mathrm{L}^{\wedge}+\alpha \mathrm{K}^{\wedge}
$$

This growth accounting version in which the capital stock is exogenous implies that the contribution of $A^{\wedge}(g)$ to the growth of output is only $(1-\alpha) A^{\wedge}$. However, an increase in $g$ unambiguously raises $\mathrm{Y}^{\wedge}$ and $\mathrm{y}^{\wedge}$. However, with neoclassical growth in which capital is endogenous, $K / Y=V$. Substituting $K \wedge=Y^{\wedge}+V^{\wedge}$ into (1) above (and rearranging $L^{\wedge}=n$ ) gets us back into the neoclassical world in which $\mathrm{y}^{\wedge}=\mathrm{g}+[\alpha /(1-\alpha)] \mathrm{V}^{\wedge}$. This exercise underscores the importance of the steady state restriction, $\mathrm{K} / \mathrm{Y}=\mathrm{V}$ by endogenizing the capital stock and substantially increasing the impact of technical change on the rate of growth. The larger $\mathrm{V}$ and the larger $\alpha$, the greater the impact of a change in g (or any of the other steady-state parameters) on $\mathrm{y}^{\wedge}$. 
Here is the difficulty associated with an increase in g: By reducing $\mathrm{K} / \mathrm{Y}$, the increase in g causes the economy to no longer be able to sustain its historic level of the capital stock at least not until $\mathrm{Y}$ has risen to a level consistent with the lower K-Y equilibrium. Hence, investment stalls, causing a precipitous decline in output and economic growth. As a result, during the transition from steady state to steady state, we see that any reduction in the capital-output ratio, brought on by an increase in g, has the potential to substantially alter both the rate of growth and the level of output per capita.

Thus, we see that with the conventional steady state condition, $\mathrm{s} /(\mathrm{n}+\mathrm{g}+\delta)$, as a condition for transitioning the economy to a higher steady state rate of technical change and growth of living standards, a substantial decline in both may be necessary.

We might refer to this condition as the Purgatory Paradox of accelerating technical change. 